U NIVERSITY OF COPENHAGEN

\title{
Tax Evasion and Swiss Bank Deposits
}

Johannesen, Niels

Publication date:

2010

Document version

Publisher's PDF, also known as Version of record

Citation for published version (APA):

Johannesen, N. (2010). Tax Evasion and Swiss Bank Deposits. Department of Economics, University of Copenhagen. 
Economic Policy Research Unit

Department of Economics

University of Copenhagen

$\varnothing$ ster Farimagsgade 5, Building 26

DK-1353 Copenhagen $\mathrm{K}$

DENMARK

Tel: (+45) 35324411

Fax: (+45) 35324444

Web: http://www.econ.ku.dk/epru/

\section{Tax Evasion and Swiss Bank Deposits}

Niels Johannesen 


\title{
Tax Evasion and Swiss Bank Deposits*
}

\author{
Niels Johannesen ${ }^{\dagger}$ \\ Department of Economics, \\ University of Copenhagen
}

This version: 30 September 2010

First version: 26 February 2009

\begin{abstract}
Bank deposits in jurisdictions with banking secrecy constitute an effective tool to evade taxes on interest income. A recent EU reform reduces the scope for this type of tax evasion by introducing a source tax on interest income earned by EU residents in Switzerland and several other jurisdictions with banking secrecy. In this paper, we estimate the impact of the source tax on Swiss bank deposits held by EU residents while using that non-EU residents were not subject to the tax to apply a natural experiment methodology. We find that the $15 \%$ source tax caused Swiss bank deposits of EU residents to drop by more than $40 \%$ with most of the response occurring in two quarters immediately before and after the source tax was introduced. The estimates imply an elasticity of Swiss deposits with respect to the net-of-source-tax-rate in the range 2.5-3.

Keywords: Tax evasion, Capital taxation, Savings Directive
\end{abstract}

\footnotetext{
*A previous version of this paper has circulated with the title 'Tax Evasion and Foreign Bank Deposits - Evidence from a Natural Experiment'

${ }^{\dagger}$ I greatly appreciate comments and suggestions by Thomas Barnebeck Andersen, Jørgen Juul Andersen, Alan Auerbach, Hilary Hoynes, Henrik Jacobsen Kleven, Claus Thustrup Kreiner, David Dreyer Lassen, Lasse Holbøll Westh Nielsen, Søren Leth-Petersen and Peter Birch Sørensen at different stages of this research project. I am grateful to the Bank for International Settlements for providing me with the dataset on cross-border deposits and for prompt and detailed answers to a large number of questions concerning the dataset. I am also indebted to Danmarks Nationalbank for hosting me while working with the data and for assisting me with technical issues. Finally, I appreciate the many valuable comments made by seminar participants at the University of Copenhagen and Danmarks Nationalbank. The views expressed in this paper are the sole responsibility of the author and do not necessarily rełect the positions of Danmarks Nationalbank and the Bank for International Settlements.
} 


\section{Introduction}

In recent years, tax evasion has moved to the center of academic debates about tax policy. Increasingly, it has been recognized that behavioral responses to taxation take many other forms than labor supply responses. This is confirmed by Feldstein (1995) and others who consistently find that taxable income is much more responsive to taxation than labor supply. This finding has spurred an interest in the wide array of behavioral responses to taxation, notably tax avoidance and tax evasion.

It is often argued that residence-based capital taxes are particularly susceptible to evasion. Since capital is internationally mobile, effective enforcement requires that tax authorities can obtain information about foreign source income. Where information exchange between tax authorities is absent, households can evade capital taxes simply by placing assets in foreign countries and not reporting the capital income. A particularly important obstacle to information exchange is banking secrecy. Almost any banking system includes some elements of secrecy in the sense that banks are required to protect the privacy of their customers by maintaining confidentiality and not disclosing information to ordinary third parties. In some jurisdictions, however, banking secrecy also severely limits the access to banking information for tax authorities and in this form banking secrecy clearly impedes effective exchange of tax relevant information. In this paper, we shall refer to jurisdictions that only to a very limited extent provide tax relevant information to other countries as offshore jurisdictions.

For obvious reasons, no exact measures exist of the revenue loss incurred by governments due to tax evasion using offshore jurisdictions. A recent report from the U.S. senate quotes estimates of the total assets held by households in offshore jurisdictions in the range $\$ 5$ - $\$ 11$ trillion and reports an estimate of the resulting global loss of tax revenue at staggering $\$ 250$ billion annually (U.S. Senate, 2008). Clearly, the use of offshore jurisdictions for tax evasion purposes is a policy issue of first-order significance. It is thus not surprising that the past decade has seen a number of notable policy responses. Individual countries have launched initiatives including amnesties for evaders disclosing offshore assets, criminal prosecution of bankers assisting with tax evasion and systematic use of bank transfer data, credit card data and client information acquired from former bank employees to identify holders of undeclared offshore wealth. Even more importantly, the OECD and the EU are both heavily involved in the fight against tax evasion and have sponsored remarkably ambitious multilateral policy initiatives.

The OECD promotes transparency and strongly encourages offshore jurisdictions to conclude bilateral tax treaties with a scope for 'information exchange upon request'. The OECD initiative has been immensely successful in the sense that, by 2009, all offshore jurisdictions had formally endorsed the OECD transparency standard and committed to conclude at least 12 bilateral treaties. While this implies that all offshore jurisdictions now have a legal mechanism allowing for provision of banking information to foreign tax authorities, it does not, by any means, imply that tax evasion has been done away with. Firstly, the incompleteness of treaty networks implies that tax evaders generally have the possibility to place assets in a jurisdiction that has no tax treaty with their country of residence. As noted, the OECD initiative obliges offshore jurisdictions to sign no more than 12 bilateral tax treaties 
and since offshore jurisdictions have been known to partly meet this obligation by concluding treaties with each other, the number of countries that are effectively able to request banking information from a given offshore jurisdiction may in some cases be considerably lower than 12 . Secondly, under the OECD guidelines requests for information must relate to a specific tax payer and "...demonstrate the foreseeable relevance of the information requested..." (OECD, 2002). In other words, information can only be obtained from the offshore jurisdiction when the tax authorities of the residence country have prior knowledge about illegal transactions and tax evaders can often eliminate the risk of detection by avoiding transactions that draw the attention of domestic tax authorities.

The EU approach to counter the use of offshore jurisdictions for evasion purposes is more pragmatic. Under the Savings Directive, a number of offshore jurisdictions are committed to apply a source tax to the interest income of EU residents and transfer $75 \%$ of the tax revenue to the residence countries. Importantly, the tax is withheld at the level of the bank paying the interest and tax authorities are not informed about the identity of the tax payer. In principle, this approach allows for taxation of foreign source interest income without challenging the banking secrecy of the cooperating offshore jurisdictions. The Savings Directive, however, has a number of loopholes that allow tax evaders to avoid the source tax. Most obviously, tax evaders may simply move assets to non-cooperating offshore jurisdictions. Alternatively, the formal ownership of assets may be transferred to an offshore trust since the Savings Directive is, loosely speaking, concerned with formal rather than beneficial ownership. Finally, bonds or bank deposits may be replaced with structured finance products with similar characteristics since the definition of interest income employed by the Savings Directive does not cover the return to such derivatives.

When considering these policy measures from an optimal policy perspective, the key parameters relate to the behavioral responses of tax evaders. Generally, it should be expected that policy measures against tax evasion are associated with an efficiency gain in terms of increased compliance. However, since policy measures typically target only a subset of all available evasion strategies, such as income earned in certain jurisdictions as under the OECD initiative or certain income types as under the EU Savings Directive, they are also likely to be associated with an efficiency loss in terms of substitution towards alternative evasion strategies. ${ }^{1}$ Arguably, the size of the compliance effect and the substitution effect determine the efficiency properties of policy measures against tax evasion. Despite the prolific policy activity, there is very little available empirical evidence on behavioral responses to changes in the international tax environment. This paper sets out to produce evidence of this sort.

The main contribution of this paper is to estimate the responses of tax evaders to the Savings Directive. The analysis is complicated by the furtive nature of tax evasion and the fact that evaded taxes are not directly observable. We take an indirect approach and estimate the effect on something presumably closely associated to evasion of taxes on interest income, Swiss bank deposits. ${ }^{2}$ Several facts

\footnotetext{
${ }^{1}$ This resembles the distinction between deterrence effects and switching effects of avoidance policies introduced by Ulph (2009). Substitution effects are not captured by standard models of tax evasion in the tradition of Allingham and Sandmo (1972) where agents have access to a single evasion strategy, under-reporting of income.

${ }^{2}$ Indirect approaches are fairly common in the empirical literature on tax evasion (Slemrod, 2007). For instance,
} 
suggest a strong link between tax evasion and Swiss bank deposits. Firstly, in the investigation of the Swiss bank UBS conducted by the U.S. Senate in 2008, UBS admitted to have 20,000 US clients with Swiss bank accounts of which only 1,000 had disclosed the accounts to the US tax authorities (U.S. Senate, 2008). Secondly, while Switzerland at least partly broke with its tradition for strict banking secrecy by endorsing the OECD transparency standard in 2009 as one of the last countries in the world, it maintained legal institutions highly attractive for foreign tax evaders and staunchly opposed OECD efforts to improve access to banking information throughout the period of our analysis. At the heart of the protection of foreign tax evaders was the legal principle of dual criminality, which implied that banking information may only be released by Swiss banks and provided to foreign tax authorities in criminal cases where the alleged offence would also constitute a criminal act under Swiss law. Since the simple non-declaration of income is not considered a criminal act under Swiss law, foreign tax evaders with Swiss bank deposits essentially had legal certainty that banking information was not transmitted to their country of residence.

We exploit that the Savings Directive increased taxes on Swiss source interest income of tax evaders resident in EU countries while not directly affecting tax evaders resident outside the EU. This allows us to apply a natural experiment methodology where the treatment group is EU residents with Swiss bank deposits and the control group is non-EU residents with Swiss bank deposits. The estimated treatment effect is large and very robust. Using a number of different control groups, we consistently find that the $15 \%$ source tax reduced bank deposits of EU residents in Switzerland by more than 40\%. Most of the estimated reduction in Swiss deposits occurred during just two quarters immediately before and after implementation of the Savings Directive, which strongly supports a causal interpretation of the estimates. The implied elasticity of Swiss deposits with respect to the net-of-tax rate is in the range 2.5-3. Using the same methodology, we estimate the impact on bank deposits in two other leading offshore centers covered by the Savings Directive, Luxembourg and Jersey. The results are in line with the estimates for Switzerland although the effects are somewhat smaller and less precisely estimated.

While our framework does not allow for a rigorous distinction between different types of behavioral responses, we argue that the estimated reduction in offshore deposits reflected substitution towards other evasion strategies rather than increased compliance. Firstly, most EU countries apply a tax rate on capital income that by far exceeds the $15 \%$ tax on offshore source interest income introduced by the Savings Directive. From the perspective of tax evaders, maintaining an offshore bank account thus clearly dominated compliance in terms of tax costs. Secondly, since the Savings Directive did not include an amnesty clause, choosing to disclose funds for tax purposes would entail a substantial risk of legal sanctions relating to tax evasion in previous years. Finally, as discussed above, other evasion strategies were readily available. Our results may thus be interpreted as an estimate of the substitutability of tax

Pissarides and Weber (1989) estimate a model of food consumption and find that self-employed spend a larger proportion of reported income on food than employees. Arguing that this finding reflects underreporting of income rather than a higher propensity to consume food, they obtain an estimate of the size of the black economy. In a more recent paper, Feldman and Slemrod (2007) apply a similar methodology using differences in charitable giving to identify the degree of underreporting. 
evasion strategies. Although it is not immediately clear to what extent our quantitative results generalize to other institutional settings, the high degree of substitutability between different tax evasion strategies found in this paper suggests that substitution severely limits the effectiveness of policy measures against tax evasion.

The paper relates to two previous studies that estimate the effect of tax variables and institutional variables on patterns of cross-border deposits. Alworth and Andresen (1992) estimate a gravity model and report modestly sized effects on deposits of the net-of-source-tax-rate. Huizinga and Nicodème (2004) estimate a panel gravity equation and find no statistically significant effects of source taxes in the preferred specification with source and residence country dummies. A key advantage of our estimates is that identification derives exclusively from the time variation in source tax rates associated with the Savings Directive. Due to scarcity of time variation in source tax rates, both previous studies rely predominantly on cross-country variation. ${ }^{3}$ A further advantage of our approach is that the different treatment of EU and non-EU residents implied by the Savings Directive provides intra-jurisdiction variation in source tax rates that enables us to identify the tax elasticity of foreign deposits in specific banking jurisdictions. This allows us to focus on Switzerland and other offshore jurisdictions where presumably the majority of foreign deposits is associated with tax evasion so that the estimated tax elasticity of foreign deposits may be interpreted as an evasion elasticity. Conversely, the existing papers estimate a single equation with all available bilateral data, which implies that estimates effectively average tax elasticities of foreign deposits across all banking jurisdictions. These estimates are difficult to interpret since small tax elasticities of foreign deposits could reflect either small evasion elasticities or a large fraction of deposits being held by non-evaders who are generally unaffected by source taxes. ${ }^{4}$

The paper is structured as follows. Section 2 lays out institutional details of the international tax environment and places the Savings Directive in this context. Section 3 describes the deposit data used in the regressions. Section 4 presents our empirical framework and discusses various threats to identification. Section 5 presents the results. Section 6 provides some concluding remarks.

\footnotetext{
${ }^{3}$ Alworth and Andresen (1992) rely exclusively on cross-border variation. In some specifications, Huizinga and Nicodème (2004) include country fixed effects, however, country-pair fixed effects would be needed to absorb all non-temporal variation.

${ }^{4}$ Two recent papers are directly concerned with the Savings Directive but employ empirical strategies that are very different from ours. Hemmelgarn and Nicodème (2009) is a policy paper from the European Commission deploying national account data, deposit data and government revenue data to assess the impact of the Savings Directive. The paper uses mostly descriptive methods and concludes that the Savings Directive had no measurable effects. Klautke and Weichenreider (2008) focus on bonds rather than deposits while exploiting that bonds issued prior to 2001 are outside the scope of the Savings Directive. The main finding is that exempt bonds are not associated with a lower pre-tax return than otherwise comparable taxable bonds, which suggests that techniques allowing investors to avoid the provisions of the Savings Directive are readily available.
} 


\section{Background}

Switzerland has a long earned reputation for banking secrecy and there is abundant anecdotal and other evidence that Swiss banks play an important role in facilitating tax evasion. ${ }^{5}$ The first part of this section describes the international tax environment relevant for households evading taxes on interest income while highlighting the institutional features that make Swiss bank deposits attractive for tax evaders. Since we aim to describe the institutional background for the Savings Directive, we focus on the rules applicable around 2005 when the Savings Directive was implemented. The second part of the section provides some details on the Savings Directive.

\subsection{The international tax environment}

Taxation of interest income is generally governed by the residence principle, hence interest income is taxable in the residence country regardless of where it is earned. To the extent that households do not self-report foreign source interest income, enforcement of the residence principle requires information exchange between tax authorities. OECD (2006) lists two conditions necessary to ensure effective exchange of information. Firstly, there must be a legal basis for exchange of information. In some countries, domestic law allows tax administrations to share information with foreign tax administrations, but more commonly the legal basis for information exchange is a bilateral agreement in the form of a Double Tax Convention or a Tax Information Exchange Agreement. Secondly, domestic tax administrations must have access to the information requested by foreign tax administrations. In the present context, the major obstacle is the banking secrecy laws that in some jurisdictions severely restrict access to banking information for domestic tax authorities.

As noted in the introduction, enforcement of the residence principle may, however, be far from perfect even when these two conditions are satisfied. Bilateral agreements typically provide for 'information exchange upon request' which has the obvious limitation that requests must relate to a specific tax payer and "...demonstrate the foreseeable relevance of the information requested..." (OECD, 2002). In other words, information can only be obtained from the source country when the tax authorities of the residence country have prior knowledge about illegal transactions. Recognizing this limitation, a number of countries engage in automatic information exchange with at least some partner countries. Clearly, automatic information exchange does not suffer from the deficiencies of information exchange upon request since it does not require that the tax authorities of the residence country have prior knowledge of irregularities.

\footnotetext{
${ }^{5}$ One source of evidence is a report from the U.S. Senate on tax haven banks and US tax compliance, which contains a thorough case study of the role of the Swiss bank UBS in facilitating tax evasion by US residents (U.S. Senate, 2008). On the finding that Swiss banks have actively marketed secret bank accounts in the US, the report states: "In 2002, UBS assured its U.S. clients with undeclared accounts that U.S. authorities would not learn of them, because the bank is not required to disclose them; UBS procedures, practices and services protect against disclosure; and the account information is further shielded by Swiss bank secrecy laws. Until recently, UBS encouraged its Swiss bankers to travel to the United States to recruit new U.S. clients, organized events to help them meet wealthy U.S. individuals, and set performance goals for obtaining new U.S. businesses" (p. 83).
} 
OECD (2006) provides a summary of the institutional features determining effective information exchange between tax administrations as of 31 December 2005. Most of the 82 countries in the survey were committed to provide information upon request to a large number of treaty partners and many countries moreover provided information to non-treaty partners on the basis of domestic law. Switzerland stands out as one of the few countries that never provided information to foreign tax authorities in cases of simple tax evasion. Under the principle of dual criminality, Switzerland only provided information in criminal cases as defined by the Swiss penal code. The legal standard used to determine criminality in tax cases was tax fraud defined as tax evasion conducted by means of false documents or the like whereas the mere non-declaration of income was not considered fraud. In cases passing the dual criminality test, Switzerland could provide information to any country on the basis of Swiss domestic law. Turning to banking secrecy, most of the surveyed countries could obtain banking information in all tax matters and in some countries banks were even required to transmit tax relevant information automatically to the tax authorities. In Switzerland, the lifting of the banking secrecy was subject to a dual criminality test, hence Swiss tax authorities did not have access to banking information in cases of simple tax evasion. In sum, the Swiss information exchange regime and banking secrecy rules offered perfect protection for foreign tax evaders using Swiss bank accounts to evade taxes on interest income in their country of residence.

Spurred by external pressure, the Swiss tax environment is currently undergoing profound changes. In May 2008, a Swiss private banker formerly employed with the Swiss bank UBS was arrested in the US on charges of conspiring with US residents to evade taxes. In June 2008, a US court demanded that UBS disclose the names of all US clients with unreported Swiss bank accounts. Meanwhile, the political pressure on offshore jurisdictions was mounting leading to a G20 agreement on a set of economic sanctions to be employed against offshore jurisdictions not complying with the OECD requirements. In March 2009, the Swiss Federal Council finally announced the commitment of Switzerland to adopt the OECD transparency standard. It is important to emphasize, however, that the current changes of the Swiss tax environment as well as preceding events that may have led tax evaders to expect future adverse changes happened after our period of analysis. The Swiss regime with a very limited legal basis for provision of information to foreign countries and almost impenetrable banking secrecy was in place and essentially unchallenged throughout the period of our analysis.

A number of other offshore jurisdictions offered a level of protection of foreign tax evaders comparable to Switzerland. Of particular interest are major financial centers that are covered by the Savings Directive and for which deposit data is available. In Luxembourg, the lifting of the banking secrecy was subject to a dual criminality test, however, the legal standard of criminality was somewhat broader than in Switzerland. ${ }^{6}$ Just like Switzerland, Luxembourg ended years of opposition to the OECD initiative by endorsing the transparency standard in March 2009. In Jersey, foreign tax evaders had been protected

\footnotetext{
${ }^{6}$ Specifically, Luxembourg lifted the banking secrecy in cases of simple non-reporting of interest income when the amount of evaded taxes was large in absolute terms or relative to the total tax liability (OECD, 2006). KPMG Luxembourg indicate on their website that tax evasion usually falls under the Luxembourg definition of tax fraud when the evaded amount exceeds $€ 100.000$ or constitutes more than $25 \%$ of the total tax liability.
} 
by a virtual absence of treaty commitments to provide information to foreign jurisdictions. In 2005, however, a treaty allowing for information exchange upon request was concluded with the US. Clearly, the signing of the treaty was likely interpreted as a more general policy change towards transparency and international cooperation and may therefore have induced behavioral responses by tax evaders that were not directly affected by the treaty. ${ }^{7}$

\subsection{The Savings Directive}

The aim of the Savings Directive is to establish effective taxation of the foreign interest income of EU resident individuals. Initially, it covered $25 \mathrm{EU}$ countries and 15 non-EU jurisdictions of which 5 were countries (i.e. Switzerland, Andorra, Liechtenstein, Monaco and San Marino) and 10 were dependent territories (i.e. Anguilla, Aruba, British Virgin Islands, Cayman Islands, Guernsey, Isle of Man, Jersey, Montserrat, Netherlands Antilles and the Turks and Caicos Islands). Negotiations between the European Commission and the 15 non-EU jurisdictions were concluded toward the end of 2004 and the Savings Directive took effect simultaneously in all participating jurisdictions on 1 July 2005. The EU enlargement on 1 January 2007 brought the number of participating jurisdictions to 42 .

The Savings Directive provides for two alternative regimes of international cooperation based on automatic information exchange and withholding taxes respectively. The first regime requires banks to report interest income earned by foreign EU residents to their local tax authorities who periodically and automatically convey this information to the tax authorities of the residence country. ${ }^{8}$ The second regime requires banks to levy a withholding tax on the interest income of foreign EU residents at $15 \%$ in 2005 gradually increasing to $20 \%$ in 2008 and $35 \%$ in 2011. Importantly, banks remit the taxes to domestic authorities with no information about the identity of the tax payers who thus remain anonymous. Since the withholding tax in the source country effectively replaces taxation in the residence country, $75 \%$ of the revenue from the tax is transferred to the residence country. While most EU countries adopted the information exchange regime, Austria, Belgium and Luxembourg as well as most of the non-EU jurisdictions including Switzerland opted for the withholding tax regime. It should be noted, however, that in any jurisdiction where the withholding tax regime is the default, individuals may avoid the withholding tax by accepting that information on interest income be automatically transmitted to their country of residence. This implies that the withholding tax effectively targets tax evaders unwilling to disclose tax relevant banking information.

\footnotetext{
${ }^{7}$ In Belgium and Austria, banking secrecy was strict relative to most other OECD countries especially because banking secrecy was normally only lifted in criminal cases, however, the effective level of protection offered to foreign tax evaders was considerably lower than in Switzerland, Luxembourg and Jersey. Both countries had extensive treaty networks providing for information exchange upon request and the absence of a dual criminality test imply that banking secrecy could be lifted in cases of simple tax evasion if considered a criminal offence in the country requesting information. In the minor financial centers Guernsey and the Isle of Man, the legal framework strongly resembled that of Jersey including the signing of a treaty with the US.

${ }^{8}$ To be precise, the STD applies not only to banks but also to other economic operators making interest payments to individuals, e.g. mutual funds, fiduciaries and financial companies other than banks.
} 
As emphasized by the European Commission (2008), the Savings Directive has a limited scope and tax evaders may circumvent its provisions in a number of ways. Firstly, geographical coverage is partial, hence moving assets to a non-participating jurisdiction is a simple and effective evasion strategy. Secondly, since the Savings Directive includes no substance-over-form test, transferring the formal ownership of assets to a trust in a non-participating jurisdiction suffices to fall outside its scope. Thirdly, investors may engage in a type of income shifting whereby interest bearing assets are replaced with structured finance products with returns linked to leading interest rates. In substance, such derivatives are identical to debt claims, yet returns are not formally interest payments and are therefore not subject to the provisions of Savings Directive.

\section{Data}

The principal source of information on cross-border deposits is the International Locational Banking Statistics of the Bank for International Settlements ('BIS'), which reports quarterly data on assets and liabilities of banks vis-a-vis foreign counterparts. The data are based on reports from individual banks compiled and aggregated by central banks and transmitted to the BIS. Currently, a total of 40 jurisdictions contribute to the banking statistics including most OECD countries, a handful of newly industrialized countries and a number of offshore financial centers. Among the offshore jurisdictions covered by the Savings Directive, Switzerland, Luxembourg, Cayman Islands, Netherland Antilles, Jersey, Guernsey and Isle of Man also report to the BIS. For the former four jurisdictions, our dataset covers the period from the fourth quarter of 1995 to the first quarter of 2008; for the latter three jurisdictions, the first observation is the fourth quarter of 2001. Observations are end-of-quarter and report values in US dollar equivalents.

We are ultimately interested in the behavioral responses to the Savings Directive and therefore construct a measure that matches the tax base of the source tax as closely as possible. The dataset contains breakdowns of bank liabilities on: (i) residence countries of counterparts; (ii) bank and nonbank counterparts, (iii) deposits and other liabilities, (iv) currency denomination. Exploiting (i)-(iii), we define $D E P_{b s t}$ as the USD value of deposits held by the non-bank sector in country $s$ in banks in country $b$ at time $t$. The measure excludes other liabilities than deposits since income from the corresponding assets may not qualify as interest under the Savings Directive and inter-bank deposits since the source tax only applies to interest income earned by households. For ease of reference, we shall simply use the term 'foreign deposits' for the deposits measured by $D E P_{b s t}$. For some reporting countries, including Cayman Islands and Netherlands Antilles, the breakdown of bank liabilities on the residence country of the counterparts is known by BIS but confidential and not included in our dataset, hence $D E P_{b s t}$ cannot be constructed for these jurisdictions. ${ }^{9}$

\footnotetext{
${ }^{9}$ The bilateral deposit data used in this paper are not publicly available, however, deposit data aggregated over individual banking or saver countries are posted on the BIS website. For Switzerland, some bilateral data are publicly available on the website of the Swiss central bank. Specifically, the Swiss central bank reports: (i) Ordinary deposits (on-balance sheet) held by foreign non-banks; (ii) Fiduciary liabilities (off-balance sheet) vis-a-vis foreign residents. Although the BIS data for
} 
The sectoral breakdown does not allow for a distinction between subgroups within the non-bank sector, hence $D E P_{b s t}$ has the undesirable feature that it includes deposits held by firms. In the case of Switzerland, there is reason to believe that foreign deposits are held predominantly by households suggesting that the latter issue is of minor importance: The extraordinarily large stocks of foreign deposits attracted by Swiss banks (documented below) strongly indicates that the bulk of these deposits are driven by tax evasion. However, the use of Swiss bank accounts to evade taxes on interest income is much less straightforward for firms than for households because financial transactions are reflected in accounts that need the approval of an external auditor. In any case, to the extent that $D E P_{b s t}$ overstates the true value of deposits held by households, it causes our estimates of behavioral elasticities to be biased towards zero.

Table 1 lists the 10 jurisdictions with the largest stocks of foreign deposits prior to implementation of the Savings Directive. Not surprisingly, large OECD countries such as the UK, the US and Germany attracted very considerable amounts of foreign deposits. A group of much smaller countries, Cayman Islands, Switzerland, Luxembourg, Singapore and Jersey, is also in the top-10. Interestingly, the small countries that attract many foreign deposits all provide a high level of legal protection to foreign tax evaders.

Figure 1 illustrates how stocks of foreign deposits in Swiss banks ('ALL') evolved over the sample period. Since the agreement between the EU and Switzerland on the Savings Directive was concluded toward the end of 2004, we consider 2004q4 a natural reference observation prior to which behavioral effects are unlikely to have occurred. We thus refer to observations before $2004 \mathrm{q} 4$ as 'pre-reform' and observations after 2004q4 as 'post-reform' and indicate the observation for 2004q4 with a vertical line in the figure. A simple comparison of pre-reform and post-reform time trends in foreign deposits does not reveal a negative effect of the source tax. On the contrary, the average annual growth rate in Swiss foreign deposits was considerably higher in post-reform years (9.3\% in 2004-2006) than in pre-reform years (3.5\% in 1996-2004). ${ }^{10}$ Since the source tax only applies to EU residents and not to non-EU residents, it is natural to compare time trends for the two groups separately. To control for the changing composition of the EU, we depict Swiss deposits held by residents of the $15 \mathrm{EU}$ member states as of the beginning of the sample period ('EU15') and Swiss deposits held by residents of the non-EU member states as of the end of the sample period ('NON-EU'). In pre-reform years (1996-2004), the average annual growth of Swiss deposits held by EU residents and non-EU residents was roughly similar (2.3\% vs. $4.2 \%$ ). Moreover, the simple correlation between quarterly growth rates for EU15 and NON-EU in Switzerland and the data published by the Swiss central bank draw on the same underlying reports by individual banks, it is not possible to reconstruct the BIS data for Switzerland with the publicly available data from the Swiss central bank owing to the following three characteristics of the latter data: Firstly, the data are annual and not quarterly. Secondly, the data contain no breakdown of fiduciary liabilities on banks and non-banks nor on deposits and other liabilities. Thirdly, observations for some jurisdictions are missing until 2005. Despite these qualifications, it is possible to construct a (more noisy) measure of the tax base of the source tax by adding (i) and (ii). Footnote 16 reports results from an application of our empirical framework to this publicly available measure of foreign deposits in Swiss banks.

${ }^{10}$ To smooth seasonal and random variation in the deposit variable over quarters, average annual growth rates are computed as growth rates in annual average levels. 
the period 1995q4 to 2004q4 was 0.66 providing some evidence of an underlying common trend in Swiss deposits for the two groups. Coinciding with the introduction of the source tax, there was a remarkable divergence in trends for EU residents and non-EU residents as evidenced by very dissimilar average annual growth rates (-9.1\% vs. $19.2 \%)$ in post-reform years (2004-2006).

\section{Empirical strategy}

The empirical strategy exploits that the Savings Directive changed the tax environment of EU residents with Swiss deposits while leaving non-EU residents with Swiss deposits unaffected. This allows us to apply a natural experiment methodology where the post-reform behavior of non-EU residents is used to proxy for the counterfactual post-reform behavior of EU residents in the absence of the Savings Directive. A key assumption in this type of framework is the ex ante comparability of control group and treatment group. While EU residents and non-EU residents differ in many respects, some of which we shall attempt to control for in the robustness checks, a crucial advantage of the Swiss institutional environment is the universality of the legal provisions protecting foreign tax evaders. The bilateral tax treaties to which Switzerland was party during our period of analysis include only very minor concessions, hence the (very limited) legal basis for provision of information to foreign tax administrations derives from Swiss domestic law, which applies universally to all foreigners regardless of their country of residence.

The empirical model simply estimates fully flexible time trends for deposits held by EU residents and non-EU residents respectively and any divergence in the two trends around the time the Savings Directive was implemented is interpreted as a causal effect of the source tax. Essentially, this is an extended version of the canonical two-period difference-in-differences model. The empirical model thus looks in the following way:

$$
\log \left(D E P_{s t}\right)=\alpha+\sum \beta_{s} D_{s}+\sum \gamma_{t} D_{t}+\sum \lambda_{t} D_{t} \times D_{E U}+\varepsilon_{s t}
$$

where $D_{s}$ is a set of country specific dummies, $D_{t}$ is a set of time dummies and $D_{E U}$ is a dummy taking the value one when $s$ is an EU member state and zero otherwise. In the central regressions, we focus on Swiss deposits, hence $D E P_{s t}=D E P_{b s t}$ for observations with $b=$ Switzerland.

The timing of the negotiations and the implementation of the Savings Directive is crucial for the interpretation of the estimates. The source tax applies to interest income earned as from 1 July 2005. In order to avoid the source tax, EU residents with Swiss bank deposits therefore needed to adopt an avoidance strategy on 30 June 2005 or before. Since the bilateral agreements with Switzerland were concluded in late 2004, we assume that anticipatory responses largely occurred after 31 December 2004 and eliminate the time dummy for 2004q4, which becomes the reference quarter of the regression. To the extent that tax evaders were unaware of the Savings Directive prior to implementation, we should expect additional learning responses after 1 July 2005 as tax evaders received bank statements showing that interest income accruing to Swiss bank accounts had been subject to a withholding tax.

The estimated treatment effect for a given post-reform quarter $t$ is captured by $\hat{\lambda}_{t}$. It is easy to 
see that $\widehat{\lambda}_{t}$ is a difference-in-difference estimator since it expresses the growth in Swiss deposits held by EU residents since 2004q4 over and above the growth in Swiss deposits held by non-EU residents since 2004q4. The interpretation of $\widehat{\lambda}_{t}$ as the causal effect of the source tax rests on the identifying assumption that the value of Swiss deposits held by EU residents and non-EU residents respectively would have followed identical growth paths after $2004 q 4$ in the absence of the Savings Directive, or equivalently, that estimating the model in a counterfactual world without the source tax would have yielded zero-estimates of $\lambda_{t}$ for post-reform quarters. There is no rigorous way to test this identifying assumption. However, it seems natural to use information from pre-reform quarters to assess its validity. In order for the identifying assumption that the value of Swiss deposits of EU residents and non-EU residents would have followed identical growth paths after 2004q4 in the absence of the Savings Directive to be credible, they should follow roughly similar growth paths until 2004q4. This implies that the estimates of $\lambda_{t}$ should generally be small and statistically insignificant for pre-reform quarters.

Even when the requirement of similar deposit growth paths in pre-reform years is satisfied, it is a cause of concern that divergence in deposit growth paths in post-reform years could be caused by a shock, which coincided with implementation of the Savings Directive and affected treatment and control groups differently. Clearly, this would invalidate the identifying assumption since the effects of such a shock would wrongly be attributed to the source tax. The most obvious shocks to take into account are the enlargements of the European Union. On 1 May 2004 and 1 January 2007, a total of 12 countries entered the EU raising the number of member states from 15 to $27 .{ }^{11}$ Importantly, the new member states adopted the entire complex of bilateral agreements between the EU and Switzerland including free trade agreements and agreements on the free movement of persons and capital. It is very plausible that these agreements had a strong independent effect on the value of Swiss bank deposits held by residents of the accession countries, which the reduced form model does not allow us to disentangle from the effect of the Savings Directive. Most regressions therefore exclude the 12 accession countries from the sample and the treatment group reduces to the 15 original EU countries ('EU15'). For the sake of completeness, separate results for the 10 countries joining the EU in 2004 ('NEW10') are also presented despite the ambiguity concerning the interpretation of these results.

In the baseline regressions, the control group includes all jurisdictions where tax evaders were unaffected by the source tax throughout the period of analysis, that is all jurisdictions except the 27 current EU countries ('NON-EU'). We also consider a number of different subsamples, each of which excludes certain jurisdictions in order to enhance comparability between treatment and control groups in a specific dimension. Firstly, we estimate the model with a control group that includes only OECD countries ('OECD'). Arguably, this reduces the risk that an asymmetric shock coinciding with the implementation of the Savings Directive and affecting industrialized and developing countries differentially invalidates the identifying assumption. Secondly, we use a control group that excludes offshore financial centers ('non-OFC'). This addresses the concern that transfer of formal ownership of Swiss deposits to offshore

\footnotetext{
${ }^{11}$ Cyprus, the Czech Republic, Estonia, Hungary, Latvia, Lithuania, Malta, Poland, Slovakia, Slovenia entered the EU on 1 May 2004 whereas Bulgaria and Romania became EU member states on 1 January 2007.
} 
trusts, an avoidance technique discussed above, may have increased observed stocks of Swiss deposits held by residents of offshore financial centers. Finally, we use a control group that excludes countries with a high share of GDP deriving from resource rents ('non-RES'). This reduces the risk that the rapid surge in commodity prices during the period 2004-2007 affected the relative size of Swiss deposits held by EU residents and non-EU residents in the control group.

Exchange rate fluctuations deserve particular attention since they mechanically affect the USD equivalent value of bank deposits denominated in other currencies. In particular, a depreciation (appreciation) of USD against other currencies mechanically increases (decreases) the USD equivalent of assets denominated in those other currencies. Since the currency denominations of Swiss deposits held by EU residents and non-EU residents differed markedly, significant exchange rate changes around the time the Savings Directive was implemented would invalidate the identifying assumption. We exploit the currency breakdown of the deposit dataset to address this concern. Specifically, letting $D E P_{\text {sta }}$ denote the USD value of Swiss deposits denominated in currency $a$ held by non-bank residents of country $s$ at time $t$, we run separate regressions with $D E P_{s t a}$ as dependent variable for each of the major currencies.

As a final note on the identification strategy, it should be emphasized that we rely crucially on the assumption that non-EU residents are unaffected by the Savings Directive. Although the provisions of the Savings Directive do not directly apply to non-EU residents, it cannot be excluded that nonEU residents are affected by general equilibrium effects. For instance, if the source tax induced EU residents to reduce their deposits in Swiss banks, the latter may have responded by raising deposit rates, which, in turn, may have affected stocks of foreign deposits. This particular possibility should not be a major concern, however, since indirect effects working through deposit rates presumably have the same impact on the treatment group and the control group thus leaving the difference-in-difference estimator unbiased. More generally, we expect general equilibrium effects to be negligible since deposits of EU residents constitute a small fraction of the total balance sheet of Swiss banks. ${ }^{12}$

The log-level formulation of the model implies that zero-observations are generally treated as missing. A common way to deal with this problem is to add a small number to the dependent variable before taking logarithms. In our context where parameters are identified by growth rates, however, this would introduce a potentially serious bias. Adding a positive number to a variable attenuates percentage changes in an asymmetric way in the sense that attenuation is stronger at low levels. Since the average level of $D E P_{s t}$ is significantly lower in the control group than in the treatment group, this procedure would thus manipulate growth rates in the dependent variable in a way that would be correlated with treatment. Noting that zero-observations constitute less than $7 \%$ of the observations in the full sample of Swiss bank deposits and even less in some subsamples, we generally allow zeroes to be treated as missing observations. ${ }^{13}$ To make sure that our results are not driven by changes in the composition of

\footnotetext{
${ }^{12}$ According to banking statistics reported by the Swiss central bank, liabilities in the form of deposits (on-balance sheet) vis-a-vis EU resident non-banks and fiduciary liabilities (off-balance sheet) vis-a-vis EU residents constituted around $0.5 \%$ and $1.6 \%$ respectively of the total balance of Swiss banks at the end of 2005 (due to missing data for France, these figures may not be computed for earlier years).

${ }^{13}$ For instance, there are no missing observations in the subsample of OECD countries
} 
the sample, we carry out robustness checks where a balanced sample property is imposed by excluding jurisdictions with at least one zero-observation from the sample.

We estimate the model using OLS. As forcefully argued by Bertrand et al. (2004), OLS standard errors may seriously understate the true standard deviation of the estimated treatment effect in the presence of serial correlation. Arguably, the problem is less severe in the present case since there are time dummies on the right-hand side rather than a persistent treatment variable. We nevertheless follow the recommendation of Bertrand et al. (2004) and present standard errors that are robust to serial correlation. $^{14}$

\section{Results}

\subsection{Main results}

In the baseline regression, we estimate the model with a sample that includes all jurisdictions except the 12 countries entering the EU in 2004 and 2007. Effectively, this estimation uses the 15 EU member states as of 1 January 2004 ('EU15') as a treatment group and all other jurisdictions than the 27 EU member states as of 1 January 2007 ('NON-EU') as a control group. The regression results are illustrated in figure 2 (numerical results in Appendix - panel A). The two lines in the figure represent the estimated trends in Swiss deposits held by EU15 and NON-EU respectively. The dashed vertical line indicates the reference quarter 2004q4. Under the identifying assumption that trends for EU15 and NON-EU would have followed the same paths absent the Savings Directive, the vertical distances between the two trend lines in post-reform quarters are the estimated treatment effects. The columns indicate the statistical significance levels ( $\mathrm{p}$-values) of the interaction terms $D_{t} \times D_{E U}$. The dashed horizontal line indicates the $5 \%$ significance level.

There is a remarkable similarity in trends for EU15 and NON-EU in pre-reform quarters followed by a striking divergence around the time the Savings Directive was implemented. Clear signs of divergence appear between observations 2005q1 and 2005q2 (i.e. between 31 March 2005 and 30 June 2005) where growth rates in the value of Swiss deposits were 3,4\% and $-13,5 \%$ for control group and treatment group respectively. Recalling that the source tax was introduced on 1 July 2005, we interpret this as an anticipatory behavioral effect. The strong divergence continues between observations 2005q2 and 2005q3 (i.e. between 30 June 2005 and 30 September 2005) with growth rates of 4,6\% and $-13,8 \%$ for NON-EU and EU15 respectively. This is probably best understood as a mix of anticipatory effects and learning effects. The source tax applies to interest income earned as from 1 July 2005, which implies that the tax cost of adopting an avoidance strategy shortly after this date was negligible. This suggests that some tax evaders anticipating the source tax might have adopted other evasion strategies shortly after 1 July 2005, which would be captured by the interaction term for 2005q3. In the subsequent four quarters (i.e. between 30 September 2005 and 30 September 2006), the average quarterly growth rate in the value of Swiss deposits was markedly lower for EU15 than for the NON-EU. We interpret this as a learning

\footnotetext{
${ }^{14}$ This is implemented in Stata with the cluster command clustering on country of residence $s$.
} 
effect in the sense that tax evaders with Swiss deposits adopted other evasion strategies after learning about the withholding tax on Swiss source interest income through bank statements or otherwise. In the remaining quarters, growth rates for NON-EU and EU15 were roughly similar. As indicated by the columns in the figure, interaction terms are clearly insignificant for all quarters up to 2005q1 and highly statistically significant for all quarters as from 2005q2 supporting the visual impression that NON-EU and EU15 followed similar paths until 2005q1 and then diverged sharply.

Estimates of the treatment effect in this specification are summarized in the first column of table 2. The choice of an appropriate time window for evaluating treatment effects is associated with the usual trade-off: A shorter window increases the risk that the estimated treatment effect does not capture all behavioral responses whereas a longer window increases the risk that the estimated treatment effect includes the effects of other shocks. In light of this trade-off, we report treatment effects for time windows of different length: The treatment effect evaluated at the end of $2005 \mathrm{q} 3$ is around $33 \% .{ }^{15}$ Essentially, this estimate only reflects behavioral responses taking place during the quarter immediately before and the quarter immediately after the implementation date and thus represents a conservative estimate, which is very unlikely to be contaminated by other events. Extending the time window by another four quarters to the end of $2006 \mathrm{q} 3$ yields an estimate of the treatment effect of around $44 \%$. By covering a period where most holders of Swiss bank deposits received bank statements indicating that a withholding tax had been levied on their interest income, this estimate presumably picks up additional learning effects. Averaging treatment effects over the four quarters of 2006 gives rise to an estimated treatment effect of $41.6 \%$. Since the latter estimate is smoothing seasonal and random variation in deposits over quarters, it represents our preferred estimate of the treatment effect. ${ }^{16}$

We also estimate the model using the 10 countries that entered the EU on 1 May 2004 ('NEW10') as treatment group and NON-EU as control group. As discussed earlier, the legal complex adopted by accession countries included bilateral agreements with Switzerland eliminating barriers to the free movement of goods, persons and capital, which presumably had a strong positive effect on Swiss bank deposits held by residents of these countries. Since the bilateral agreements came into force shortly before we would expect anticipatory responses to the Savings Directive, the regression results should be interpreted with caution.

The results are illustrated in figure 3 (numerical results in Appendix - panel B). Time trends for NON-EU and NEW10 are fairly similar from 2000 through 2004 and relatively clear signs of divergence appear around the time the Savings Directive was implemented. Between observations 2005q1 and 2005q3 (i.e. between 31 March 2005 and 30 September 2005), growth rates in the value of Swiss deposits

\footnotetext{
${ }^{15}$ The treatment effect for period $t$ is computed as $\exp (0)-\exp \left(\widehat{\lambda}_{t}\right)$ for post-STD values of $t$ where 0 under the identifying assumption is the expected, counterfactual value of $\widehat{\lambda}_{t}$ absent the STD.

${ }^{16}$ Estimating the model with the publicly available data from the website of the Swiss Central Bank described in footnote 9 yields very similar results. The data are end-of year and cover the period 2002-2008. We let 2004 be the reference year and omit time dummies for this year. In line with the reported results for the baseline model, the interaction terms for 2002 and 2003 are statistically insignificant whereas interaction terms for 2005, 2006, 2007 and 2008 are statistically significant at the $1 \%$ level with implied treatment effects in the range $-44 \%$ to $-37 \%$.
} 
were $8,2 \%$ and $-12,1 \%$ for NON-EU and NEW10 respectively. Supporting this interpretation of the figure, interaction terms for all quarters from 2000q1 through 2004q4 are clearly insignificant whereas interaction terms for 2005q3-2006q1 are negative and statistically significant. After 2005q4, the average growth rate in the value of Swiss deposits is higher for NEW10 than for NON_EU and the two time trends converge again. Interaction terms for all quarters as from 2006q2 are statistically insignificant.

Since the identifying assumption that time trends for NON-EU and NEW10 would have been similar absent the Savings Directive is not credible in light of the almost simultaneous adoption of bilateral agreements with a potentially large impact on Swiss deposits, we refrain from interpreting coefficients on interaction terms as causal effects of the source tax. It is reassuring, however, that in the short time window where we should expect behavioral responses to the source tax to be strongest, the divergence in time trends for NON-EU and NEW10 is statistically significant and not much smaller than the divergence in the time trends for NON-EU and EU15.

\subsection{Robustness checks}

As a first robustness check of the large treatment effects found for the treatment group EU15, we estimate the model with a control group that only includes OECD member states ('OECD'). This reduces the size of the control group from 177 countries to 10 countries, however, arguably increases the comparability between treatment and control groups by excluding developing countries from the sample. The results are illustrated in figure 4 (numerical results in Appendix - panel C). Somewhat surprisingly in light of the very considerable reduction in sample size, the results are almost identical to the baseline results. As reported in the second column of table 2, the implied treatment effects are $36.3 \%$ and $44.8 \%$ when evaluating at the end of 2005q3 and 2006q3 respectively and 41.1\% when averaging over the four quarters of 2006 .

We also estimate the model with Swiss deposits denominated in each of the four major currencies EUR, USD, CHF and GBP separately. ${ }^{17}$ As noted earlier, exchange rate fluctuations mechanically affect the USD equivalent value of bank deposits in other currencies. Since the currency composition of Swiss deposits differed considerably between EU residents and non-EU residents, significant exchange rate changes around the time the Savings Directive was implemented could potentially invalidate our identifying assumption. Under the assumption that there were no behavioral responses to the source tax and the treatment effects estimated in the baseline model exclusively reflect exchange rate movements, we should find zero treatment effects in the currency specific regressions. Under the alternative assumption that the treatment effects estimated in the baseline model reflect true behavioral responses, we should find negative treatment effects in at least some of the currency specific regressions and, moreover, the weighted average of these currency specific treatment effects should be roughly identical to the baseline treatment effect when weights equal the currency shares in the total value of Swiss deposits held by

\footnotetext{
${ }^{17}$ In 2004q4, more than $95 \%$ of Swiss deposits were denominated in one of these four currencies. Not surprisingly, there were substantial differences in the currency composition between EU15 (EUR: 46\%; USD: 26\%; CHF: 16\%; GBP: 9\%) and NON-EU (EUR: 20\%; USD: 62\%; CHF: 6\%, GBP: 8\%).
} 
EU residents. The results are illustrated in figure 5a-5d (numerical results in Appendix - panel D-G). Although patterns differ across currencies, the trends for EU15 and NON-EU clearly diverge around 2005q2-2005q3 for all four currencies. As reported in table 2, the implied treatment effects range from $-20.5 \%$ ( CHF) to $-44.7 \%$ (GBP) when evaluated at the end of $2005 \mathrm{q} 3$ and from $-25.8 \%$ (CHF) to $-56.9 \%$ (GBP) when evaluated at the end of 2006q3. Table 2 also displays weighted averages of the currency specific treatment effects using currency shares in Swiss deposits held by EU residents as of 2004q4 as weights. The weighted averages are remarkably similar to the treatment effects from the baseline regression suggesting that the latter results are not to any significant extent driven by exchange rate movements.

Turning to a caveat related to the notion of compositional change, we recall that transferring the formal ownership of interest bearing assets to a trust located in a jurisdiction not covered by the Savings Directive allows EU residents to escape the source tax. The use of this particular avoidance technique poses a threat to our identification strategy since it translates into a drop in foreign deposits held by EU residents and an increase in foreign deposits held by non-EU residents, the latter causing the differencein-differences estimators to suffer from an upward bias. In an attempt to address this concern, we identify the jurisdictions most likely to host trust business and construct a modified control group that excludes these jurisdictions. Due to recent legislative innovation, most of the global trust business is now located in offshore jurisdictions. ${ }^{18}$ We thus estimate the model with an alternative control group that excludes 46 offshore financial centers ('NON-OFC') as classified by the IMF (Zorome, 2007). As reported in table 2, implied treatment effects with control group NON-OFC are only slightly smaller than the baseline results. $^{19}$

A specific shock to the world economy more or less coinciding with the implementation of the Savings Directive was a rapid surge of commodity prices. ${ }^{20}$ Since EU countries are net importers and non-EU countries are net exporters of primary commodities, there is a risk that the commodity price boom had an independent effect on the size of foreign assets held by EU residents relative to the size of foreign assets held by non-EU residents, which could potentially invalidate our identifying assumption. To address this concern, we use data from the World Development Indicators database on the value of rents associated with extraction of fossil fuels and minerals to construct a control group that excludes countries with a high share of GDP deriving from resource rents ('NON-RES'). Specifically, we estimate the model with a sample that excludes 21 countries where resource rents accounted for more than $30 \%$ of GDP in 2004 . As reported in table 2, treatment effects with control group NON-RES are almost identical to the baseline results.

We conduct two final robustness checks with the Swiss deposit data. As discussed earlier, the log-level

\footnotetext{
${ }^{18}$ Lorenzetti (1997) argues that offshore trusts have two main advantages over onshore alternatives. Firstly, they offer better asset protection from the claims of creditors (e.g. tax administrations). Secondly, they allow the settlor to retain a large degree of control over assets even in the case of discretionary trusts.

${ }^{19}$ Due to space constraints, we do not list numerical results for this regression and the following robustness checks but simply report implied treatment effects.

${ }^{20}$ According to the IMF Primary Commodity Price Index, average commodity prices more than doubled from 2004 to 2008.
} 
formulation of the model implies that zero-observations are treated as missing. To make sure that our results are not driven by changes in the composition of the sample, we carry out robustness checks where a balanced sample property is imposed by excluding jurisdictions with at least one zero-observation from the sample ('BAL'). Moreover, the fact that $D E P_{b s t}$ is reported in integer number of USD millions introduces some measurement error, which is particularly pronounced for country pairs where the level of $D E P_{b s t}$ is low. There is a priori no reason to believe that this type of measurement error should be correlated with treatment and rounding should therefore not bias our estimates. As a crude test of whether observations with potentially large measurement errors influence the results, we estimate the model with a control group that excludes countries for which stocks of Swiss deposits take values below 10 million dollars in any quarter during the sample period ('10MIO'). As reported in table 2, implied treatment effects are almost identical to the baseline estimates.

\subsection{Other banking jurisdictions}

As a final robustness check, we apply the same empirical framework to Luxembourg and Jersey. These are both offshore jurisdictions providing foreign tax evaders with a high level of protection against detection and are both among the ten jurisdictions in the world that attract most foreign deposits. For each of the two banking jurisdictions, we estimate the model using EU15 as treatment group and NON-EU and OECD as control groups in two separate regressions. ${ }^{21}$

Firstly, we consider Luxembourg. The regression results with control group NON-EU are illustrated in figure 6 (numerical results in Appendix - panel I). There are some signs of divergence around the time the Savings Directive was implemented. Specifically, between observations 2005q1 and 2005q4 (i.e. between 31 March 2005 and 31 December 2005), growth rates in the value of Luxembourg deposits were 1,6\% and -16,1\% for NON-EU and EU15 respectively. Interaction terms in post-reform quarters, however, are in most cases statistically insignificant. The regression results with control group OECD are illustrated in figure 7 (numerical results in Appendix - panel J). In the same three quarters 2005q1-2005q4, the growth rate was $35,4 \%$ for OECD suggesting a much larger treatment effect than when using the control group NON-EU. It should be noted, however, that average growth rates in Luxembourg deposits during the years prior to implementation of the Savings Directive were higher for OECD than for EU15, which casts some doubt on the identifying assumption of similar growth rates in post-reform quarters absent the

\footnotetext{
${ }^{21}$ Although in principle our methodology is applicable to any banking jurisdiction for which bilateral deposit data is available, we limit the analysis to jurisdictions where there are strong a priori reasons to believe that a large fraction of foreign deposits is owned by tax evaders. In such jurisdictions behavioral responses by tax evaders translate into relatively large and detectable changes in $D E P_{s t}$ whereas in jurisdictions where foreign tax evaders account for a small fraction of total foreign deposits even considerable behavioral responses to the Savings Directive cause relatively little and hardly detectable variation in $D E P_{s t}$. In other words, since we are unable to distinguish deposits owned by evaders and nonevaders in the data, analyzing jurisdictions that attract many tax motivated deposits increases the statistical power of the tests. Moreover, only in cases where we have strong priors that a large fraction of total deposits is owned by tax evaders, it is natural to interpret the estimated tax elasticity of $D E P_{s t}$ as an approximation to the theoretically relevant evasion elasticity. It would have been natural to include the Cayman Islands in the analysis, however, our dataset does not contain bilateral deposit data for this jurisdiction.
} 
Savings Directive. Moreover, coefficients have large standard errors and interaction terms in post-reform quarters are not consistently significant at the $5 \%$ level. In table 3, we report the estimated treatment effects in Luxembourg for different time windows. Treatment effects are in the range $-15 \%$ to $-10 \%$ when using NON-EU as control group and in the range $-32 \%$ to $-27 \%$ when using OECD as control group.

Secondly, we consider Jersey. The regression results are illustrated in figure 8-9 (numerical results in Appendix - panel K-L). In both figures, there are strong signs of divergence between observations 2005q1 and 2005q3 (i.e. between 31 March 2005 and 30 September 2005). A peculiar feature of the trend line for EU15 is the spikes in 2006q2 and 2007q4. Both spikes are due to sudden increases in Jersey deposits from a few jurisdictions (i.e. Germany, Belgium and Luxembourg) followed by a decrease of a similar magnitude in the next quarter. In terms of statistical significance, we note that interaction terms for all quarters after 2005q2 (except the two quarters with spikes) are highly significant. Estimated treatment effects for Jersey are reported in table 3 and fall in the range $-30 \%$ to $-17 \%$ for control group NON-EU and $-32 \%$ to $-22 \%$ for control group OECD.

\subsection{Implied behavioral elasticities}

Our preferred estimate of the reduction in Swiss deposits caused by the Savings Directive is around $42 \%$. The $15 \%$ source tax reduced the net-of-tax rate from 1 to 0.85 , hence the implied elasticity of Swiss bank deposits with respect to the net-of-tax rate is around 2.75. Our other estimates of the reduction in Swiss deposits caused by the Savings Directive range from $-45 \%$ to $-30 \%$ thus implying a tax elasticity of Swiss bank deposits in the interval 2-3. In Luxembourg and Jersey, the tax elasticity of foreign bank deposits implied by the results varies between 0.7 and 2 depending on the time window and the control group.

As noted earlier, the source tax only affects evading households whereas firms fall outside the scope of the tax and non-evading households may easily avoid the tax by allowing offshore banks to disclose information that is self-reported to the tax authorities in any case. To the extent that our empirical measure of offshore deposits $D E P_{b s t}$ also includes other types of deposits, the responsiveness of tax evaders is even higher than suggested by the above estimates. Assuming, for instance, that $20 \%$ of the offshore deposits captured by the empirical deposit measure were held by firms and non-evading households, the estimated reduction in total Swiss deposits of around $42 \%$ corresponds to a reduction in deposits held by evading households of around $52 \%$ implying a tax elasticity of around 3.5. In other words, the fact that our empirical measure of offshore deposits is broader than the tax base to which the source tax applies means that the elasticity estimates presented above are lower bounds for the true responsiveness of tax evaders with offshore deposits.

\section{Concluding remarks}

The main aim of the paper was to estimate the impact of the Savings Directive on Swiss bank deposits held by EU residents. We found very robust results suggesting that the $15 \%$ source tax on interest 
income introduced by the Savings Directive caused Swiss bank deposits of EU residents to decrease by more than $40 \%$ corresponding to an elasticity of deposits with respect to the net-of-tax rate around 2.75. We also presented less conclusive evidence suggesting somewhat smaller effects in Luxembourg and Jersey.

There are important reasons to believe that the estimated reduction in offshore deposits reflected substitution towards other evasion strategies rather than increased compliance. Firstly, most EU countries apply a tax rate on capital income that by far exceeds the $15 \%$ tax on offshore source interest income introduced by the Savings Directive. From the perspective of tax evaders, maintaining an offshore bank account thus clearly dominated compliance in terms of tax costs. Secondly, since the Savings Directive did not include an amnesty clause, choosing to disclose funds for tax purposes would entail a substantial risk of legal sanctions relating to tax evasion in previous years. Finally, as discussed above, other evasion strategies were readily available. For these reasons, we believe that our results represent a relatively clean estimate of the substitutability of tax evasion strategies in the context of the Savings Directive. Arguably, the efficiency loss associated with substitution towards other evasion strategies is counterbalanced by an efficiency gain due to increased compliance. This gain is presumably dynamic in nature in the sense that the source tax likely deters future tax evasion rather than causes existing offshore deposits to be repatriated. Our empirical framework is not suited to provide an estimate of the compliance effect of the Savings Directive.

As is often the case with estimates of behavioral elasticities derived in non-structural frameworks, the question of external validity arises. Clearly, the extent to which tax evaders are able to circumvent measures against tax evasion depends partly on the degree of sophistication of tax evaders and partly on the particular design of the measures themselves, hence our sizable estimates of the responsiveness of tax evasion strategies do not necessarily carry over to other types of policy measures. In some dimensions, such as the definition of interest income and the test of beneficial ownership, the scope of the Savings Directive is certainly narrow, which presumably increases the substitutability between targeted and non-targeted evasion strategies. On the other hand, the Savings Directive is a rare example of a truly multilateral reform comprising a large group of tax havens and other financial centers. Presumably, the behavioral responses of tax evaders to an otherwise similar bilateral reform would have been even larger since substitution towards bank deposits in non-targeted jurisdictions would have been easier. In this light, the high degree of substitutability between different tax evasion strategies found in this paper suggests that substitution severely limits the effectiveness of policy measures against tax evasion.

\section{References}

Allingham, M. G., Sandmo, A., 1972. Income tax evasion: A Theoretical Analysis. Journal of Public Economics 1, 323-338.

Alworth, J.S., Andresen, S., 1992. The determinants of cross-border non-bank deposits and the competitiveness of financial market centres. Money Affairs 5, 105-133. 
Bertrand, M., Duflo, E. and Mullainathan, S., 2004. How Much Should We Trust Differences-inDifferences Estimates? Quarterly Journal of Economics, February, 249-275.

European Commission, 2008. Report from the Commission to the Council, COM(2008) 552 final.

Feldman, N.E., Slemrod, J., 2007. Estimating tax noncompliance with evidence from unaudited tax returns. Economic Journal 117 (March), 327-352.

Feldstein, M.S., 1995. The Effect of Marginal Tax Rates on Taxable Income: A Panel Study of the 1986 Tax Reform Act. Journal of Political Economy 103(3), 551-572.

Hemmelgarn, T., Nicodème, G., 2009. Tax Co-ordination in Europe: Assessing the First Years of the EU Savings Tax Directive. European Commission Taxation Papers No. 18.

Huizinga, H. and Nicodème, G., 2004. Are international deposits tax-driven. Journal of Public Economics 88, 1093-1118.

Klautke, T., Weichenreider, A.J., 2008. Interest Income Tax Evasion, the EU Savings Directive, and Capital Market Effects. CESifo Working Paper No. 2300.

Lorenzetti, J.T., 1997. The Offshore Trust: A Contemporary Asset Protection Scheme. Commercial Law Journal 102, 138-165.

OECD, 2002. Model Agreement on Exchange of Information on Tax Matters

OECD, 2006. Tax Cooperation - Towards a Level Playing Field.

OECD, 2010, Promoting Transparency and Exchange of Information for Tax Purposes.

Pissarides, C.A., Weber, G., 1989. An Expenditure-Based Estimate of Britain's Black Economy. Journal of Public Economics 39(1), 17-32.

Slemrod, J., 2007. Cheating Ourselves: The Economics of Tax Evasion. Journal of Economic Perspectives $21(1), 25-48$

Ulph, D., 2009. Avoidance Policies - A New Conceptual Framework. Oxford University Centre for Business Taxation Working Paper WP09/22.

U.S. Senate, 2008. Tax Haven Banks and U.S. Tax Compliance. Staff Report, Permanent Subcommittee on Investigations. 


\section{Appendix A - Tables and Figures}

Table 1: Foreign deposits by banking jurisdiction in 2004 (USD billions)

\begin{tabular}{lr}
\hline \hline United Kingdom & 882,0 \\
United States & 514,6 \\
Cayman Islands & 475,9 \\
Germany & 400,1 \\
Switzerland & 331,0 \\
Luxembourg & 165,2 \\
Belgium & 158,2 \\
Singapore & 141,0 \\
Spain & 134,3 \\
Jersey & 114,6 \\
\hline ALL & 4224,9 \\
\hline \hline
\end{tabular}

Note: The annual level is computed as a simple average over quarters 
Table 2: Estimated treatment effects for Switzerland

\begin{tabular}{|c|c|c|c|c|c|c|c|c|c|c|c|}
\hline Treatment group & EU15 & EU15 & EU15 & EU15 & EU15 & EU15 & EU15 & EU15 & EU15 & EU15 & EU15 \\
\hline Control group & NON-EU & OECD & NON-EU & NON-EU & NON-EU & NON-EU & NON-EU & NON-OFC & NON-RES & BAL & $10 \mathrm{MIO}$ \\
\hline Currency denomination & ALL & ALL & EUR & USD & $\mathrm{CHF}$ & GBP & Average & ALL & ALL & ALL & ALL \\
\hline Column & 1 & II & II & IV & V & VI & VII & VIII & IX & $x$ & $X I$ \\
\hline \multicolumn{12}{|l|}{ Evaluation } \\
\hline - 30 sepember 2005 & $-33,3 \%$ & $-36,3 \%$ & $-35,6 \%$ & $-33,8 \%$ & $-20,5 \%$ & $-44,7 \%$ & $-33,4 \%$ & $-32,2 \%$ & $-32,0 \%$ & $-34,6 \%$ & $-32,9 \%$ \\
\hline - 30 sepember 2006 & $-44,3 \%$ & $-44,8 \%$ & $-42,0 \%$ & $-51,6 \%$ & $-25,8 \%$ & $-56,9 \%$ & $-43,2 \%$ & $-42,1 \%$ & $-43,6 \%$ & $-42,7 \%$ & $-42,6 \%$ \\
\hline - average 2006 & $-41,6 \%$ & $-41,1 \%$ & $-42,5 \%$ & $-48,2 \%$ & $-22,9 \%$ & $-55,6 \%$ & $-41,9 \%$ & $-39,8 \%$ & $-40,8 \%$ & $-40,9 \%$ & $-40,0 \%$ \\
\hline
\end{tabular}

Table 3: Estimated treatment effects for Luxembourg and Jersey

\begin{tabular}{lcccc}
\hline \hline Banking country & Luxembourg & Luxembourg & Jersey & Jersey \\
Treatment group & EU15 & EU15 & EU15 & EU15 \\
Control group & NON-EU & OECD & NON-EU & OECD \\
Currency denomination & ALL & ALL & ALL & ALL \\
Column & I & II & III & IV \\
& & & & \\
Time window & & & & \\
- 30 sepember 2005 & $-11,5 \%$ & $-26,7 \%$ & $-30,4 \%$ & $-32,0 \%$ \\
- 30 sepember 2006 & $-14,9 \%$ & $-31,7 \%$ & $-28,3 \%$ & $-31,0 \%$ \\
- average 2006 & $-9,5 \%$ & $-27,8 \%$ & $-16,8 \%$ & $-21,7 \%$ \\
\hline \hline
\end{tabular}


Figure 1: Foreign deposits in Swiss banks

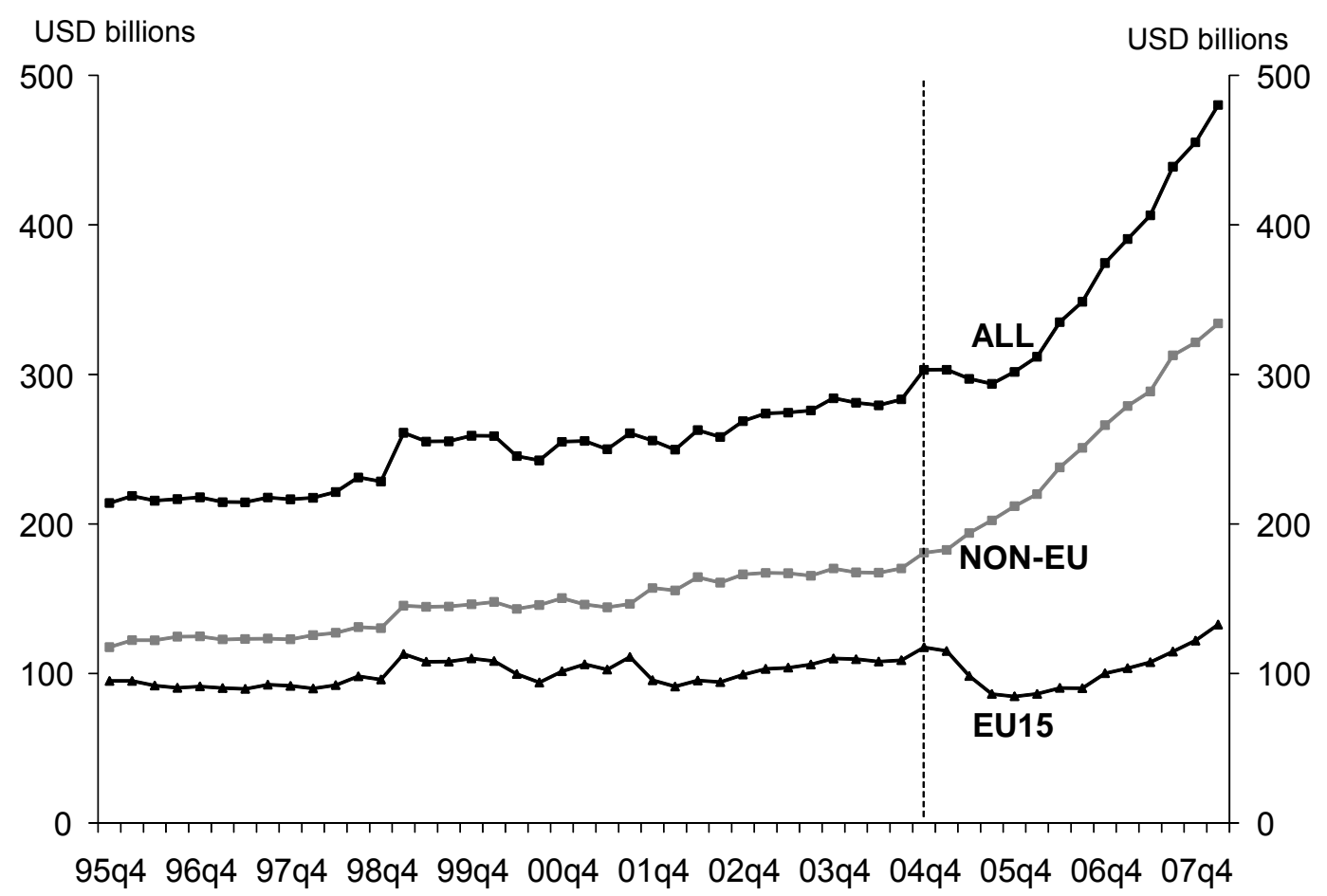

Figure 2: Swiss deposits, EU15 vs. NON-EU

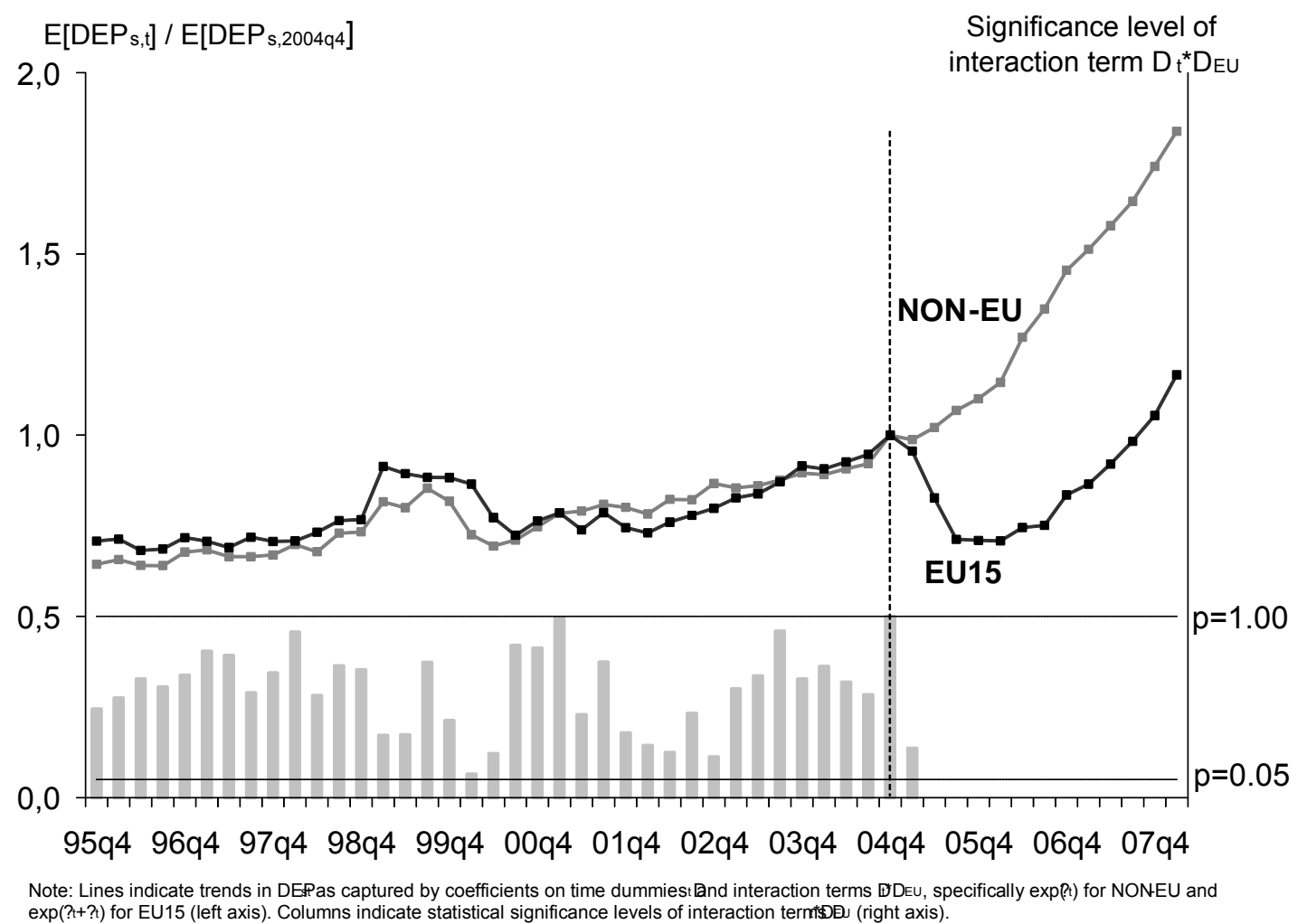


Figure 3: Swiss deposits, NEW10 vs. NON-EU

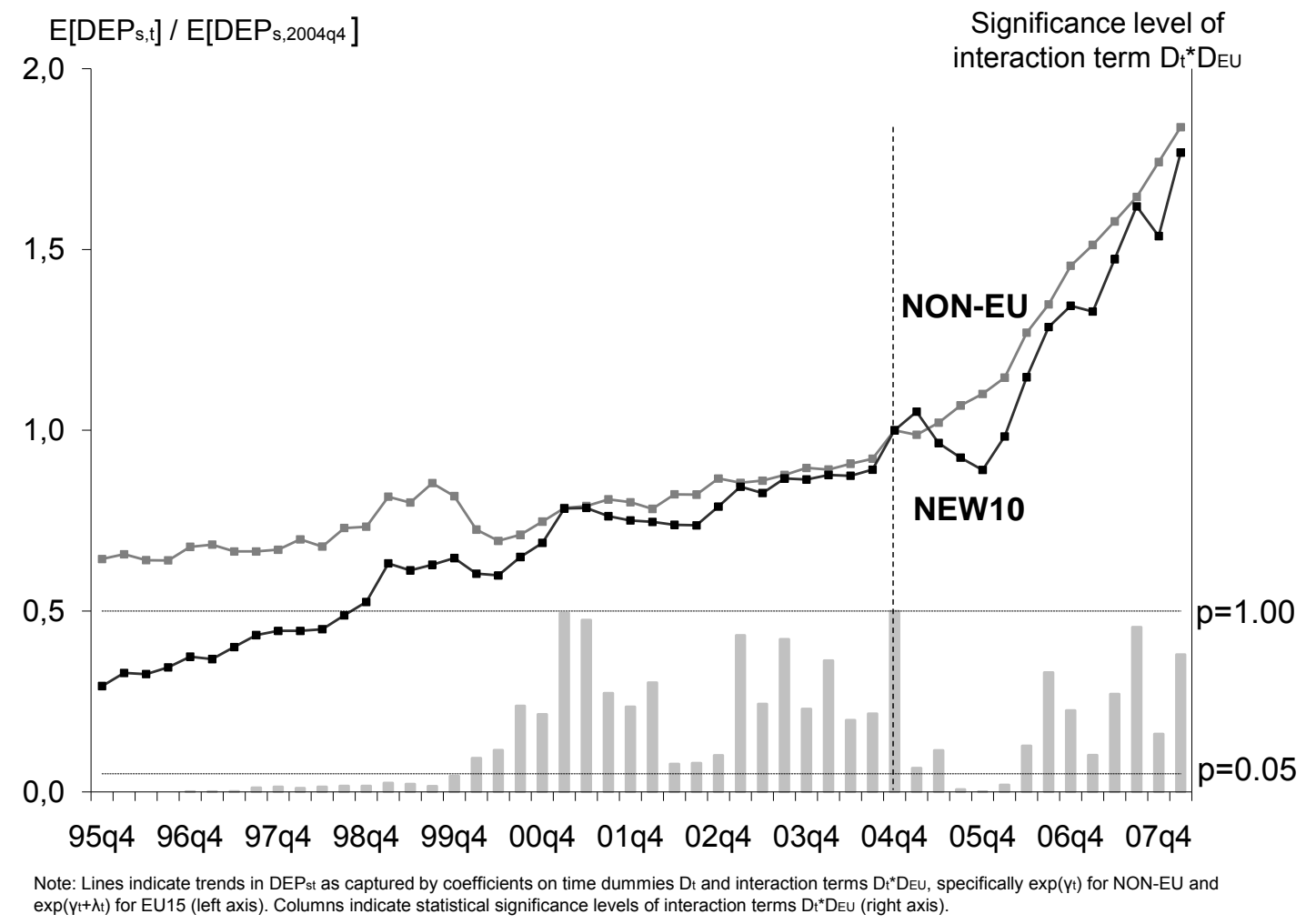

Figure 4: Swiss deposits, EU15 vs. OECD

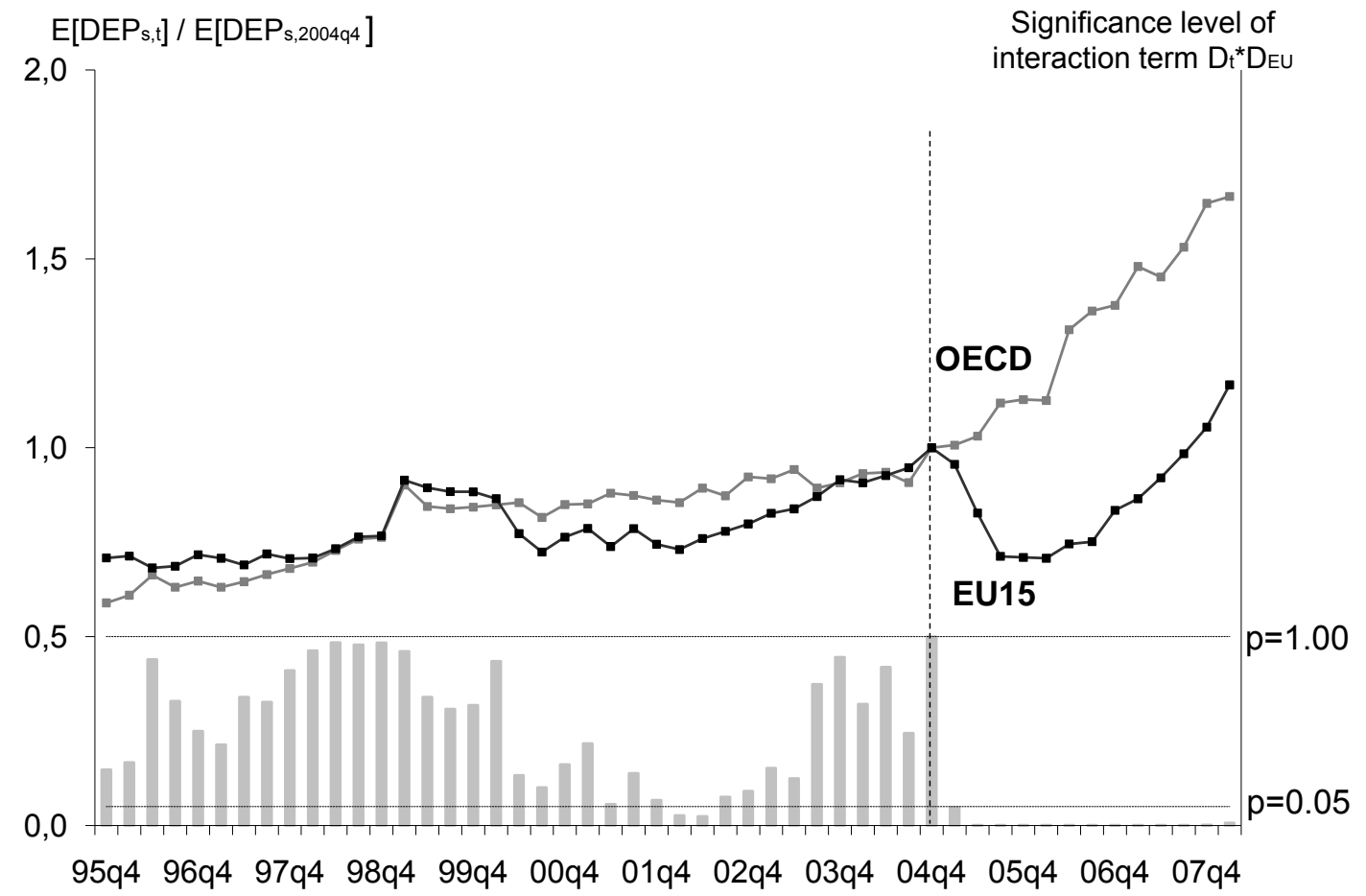

Note: Lines indicate trends in DEPst as captured by coefficients on time dummies $D_{t}$ and interaction terms $D_{t}^{*} \mathrm{DEU}_{\mathrm{U}}$, specifically $\exp \left(\mathrm{Y}_{\mathrm{t}}\right)$ for NON-EU and

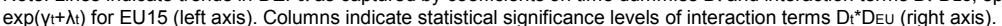




\section{Figure 5a: EUR denominated Swiss deposits}

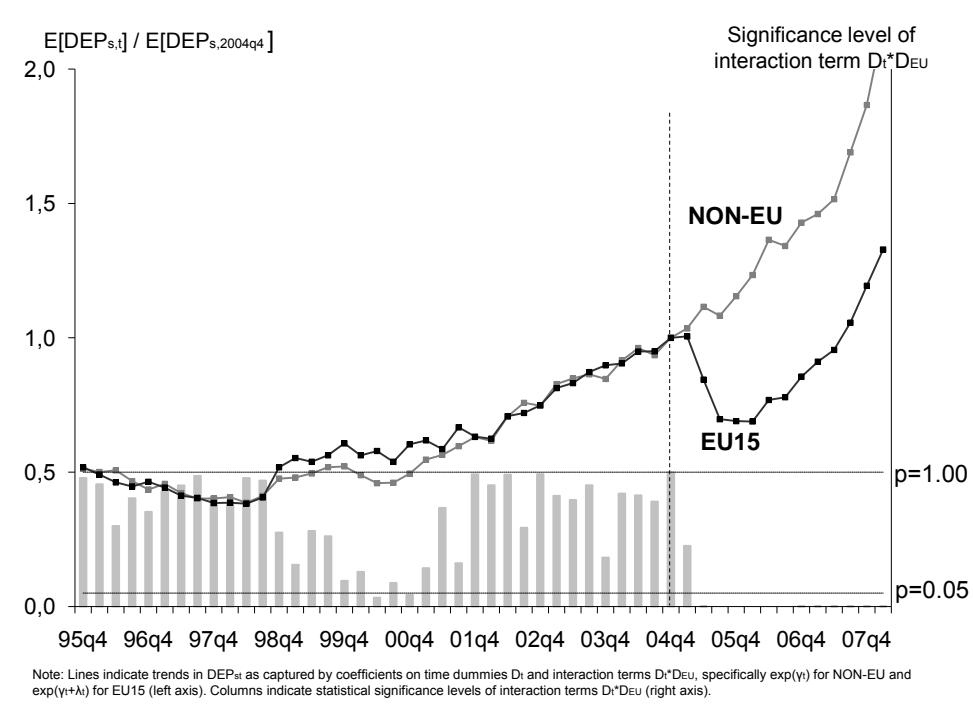

Figure 5c: CHF denominated Swiss deposits

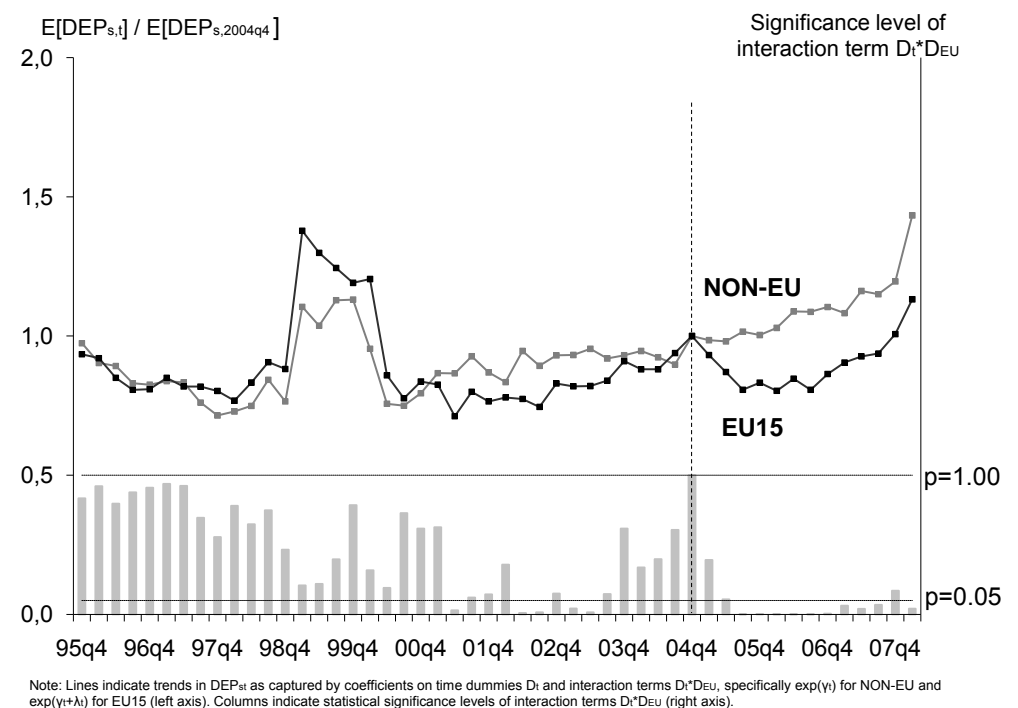

\section{Figure 5b: USD denominated Swiss deposits}

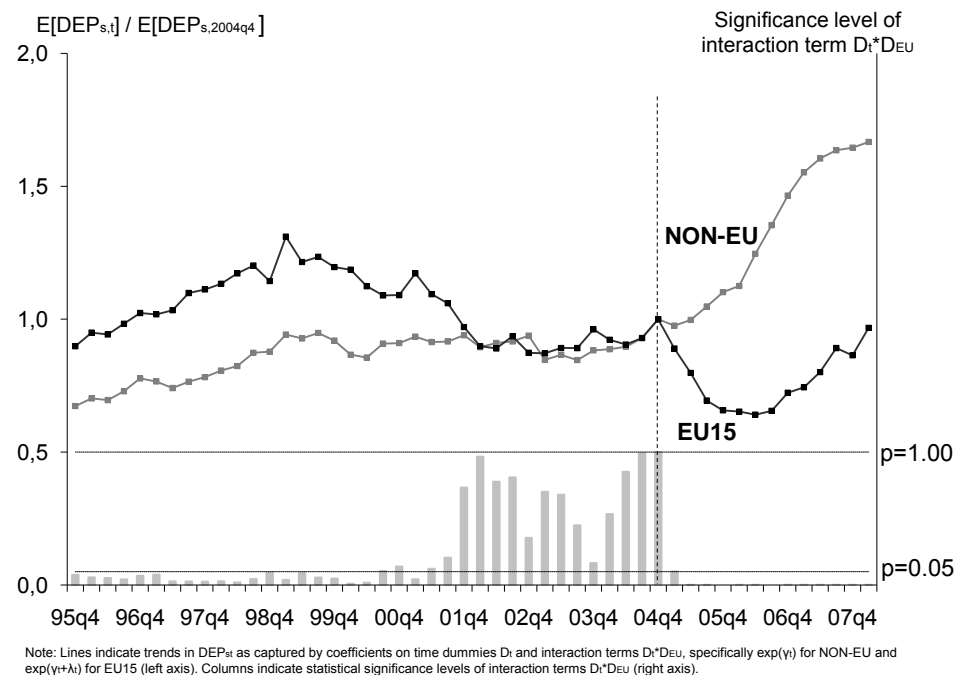

Figure 5d: GBP denominated Swiss deposits

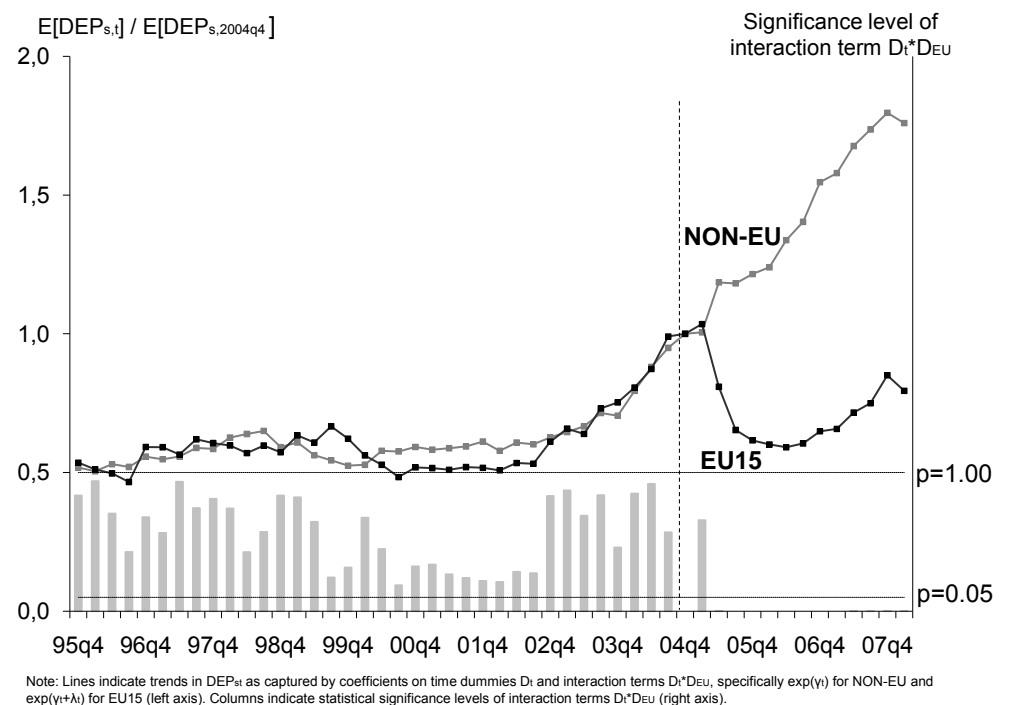


Figure 6: Luxembourg deposits, EU15 vs. NON-EU

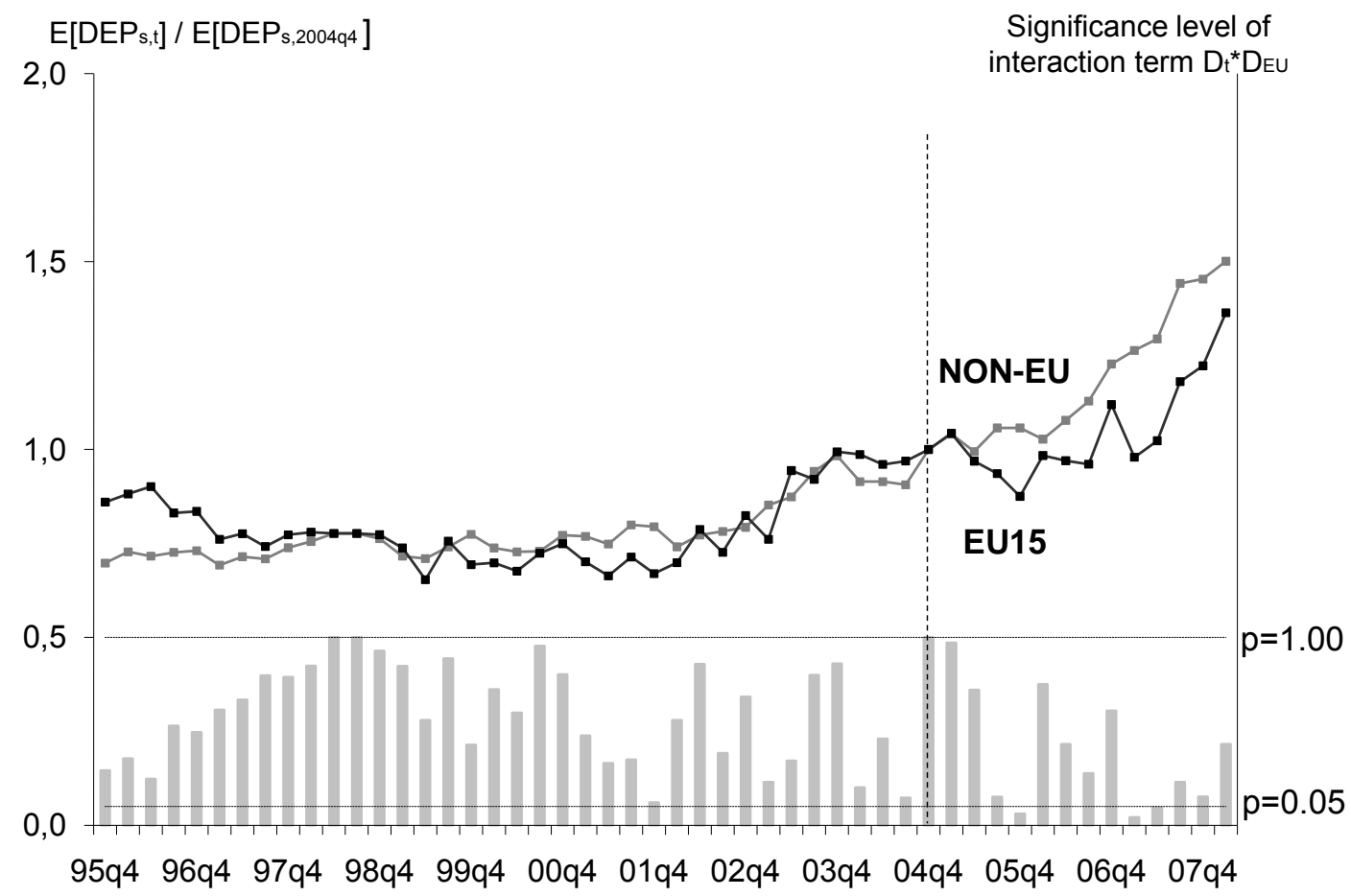

Note: Lines indicate trends in DEPst as captured by coefficients on time dummies $D_{t}$ and interaction terms $D_{t}^{*} D_{E U}$, specifically $\exp \left(\mathrm{Yt}_{\mathrm{t}}\right)$ for NON-EU and $\exp \left(\mathrm{y}_{\mathrm{t}}+\lambda_{\mathrm{t}}\right)$ for EU15 (left axis). Columns indicate statistical significance levels of interaction terms $\mathrm{Dt}^{*} \mathrm{DEU}$ (right axis).

Figure 7: Luxembourg deposits, EU15 vs. OECD

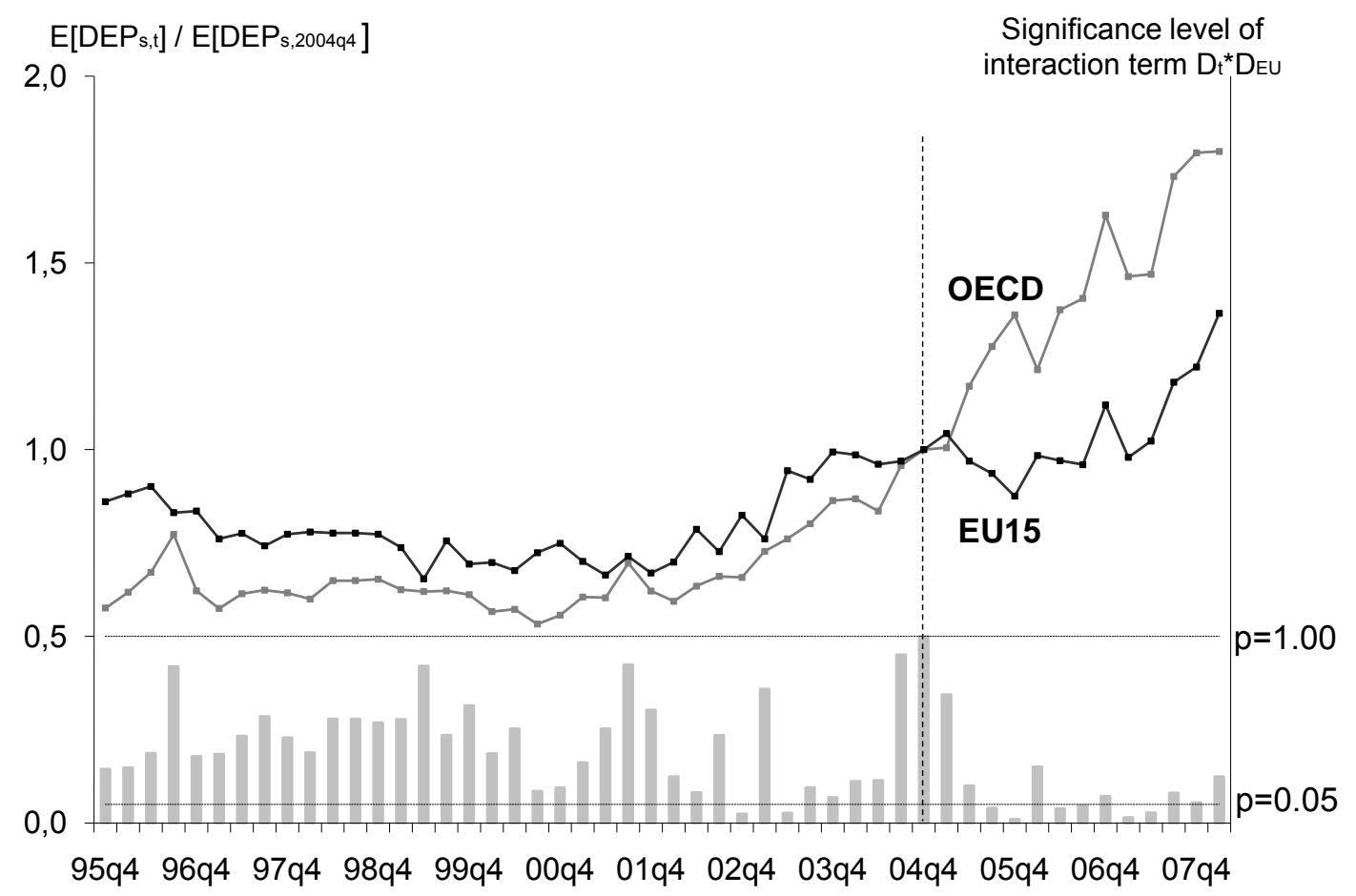

Note: Lines indicate trends in DEPst as captured by coefficients on time dummies $D_{t}$ and interaction terms $D_{t}^{*} D E U$, specifically exp( $\left(\mathrm{Yt}^{t}\right)$ for NON-EU and $\exp \left(\gamma_{t}+\lambda_{t}\right)$ for EU15 (left axis). Columns indicate statistical significance levels of interaction terms $D_{t}^{*} D_{E U}$ (right axis). 
Figure 8: Jersey deposits, EU15 vs. NON-EU

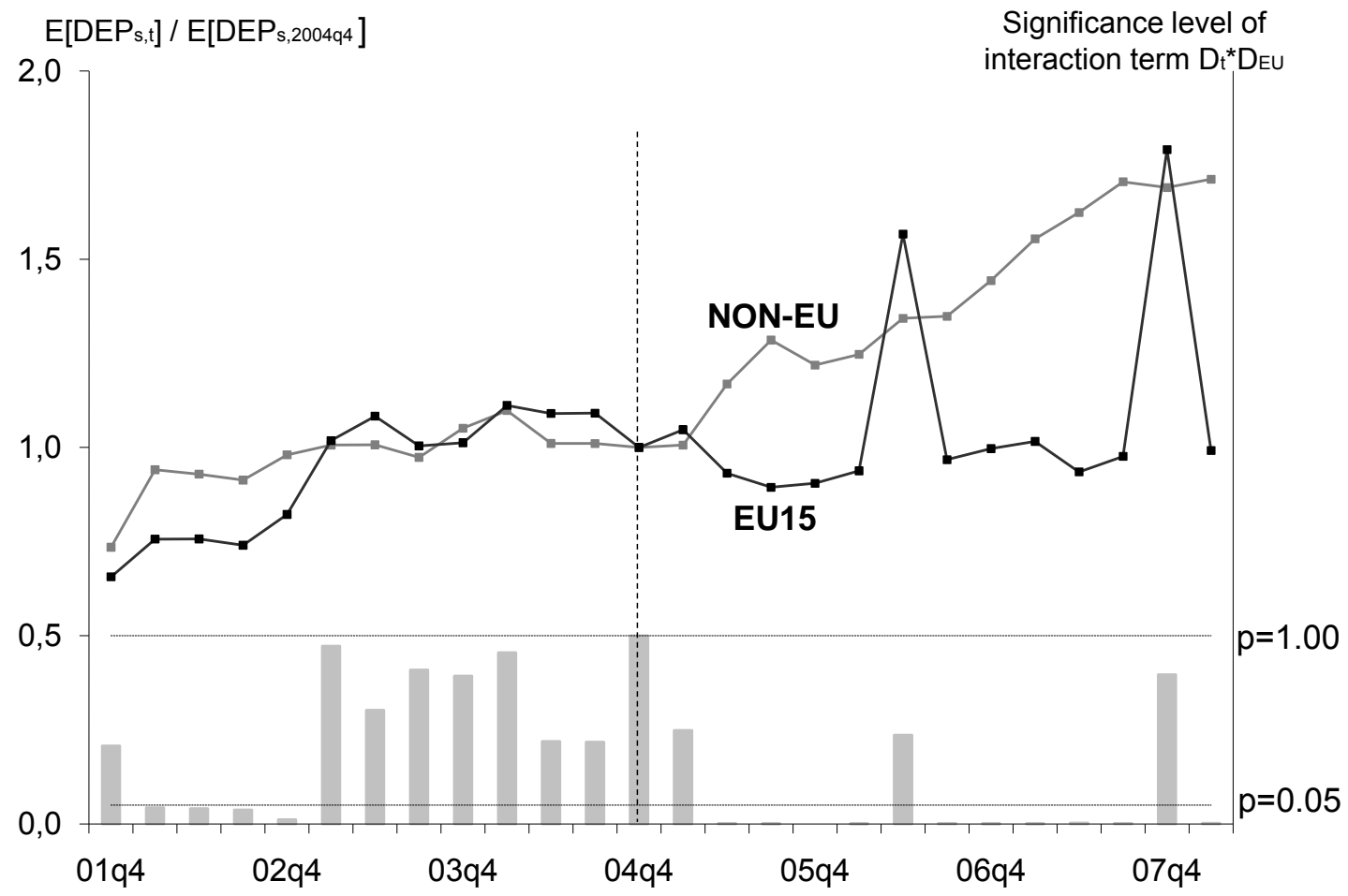

Note: Lines indicate trends in DEPst as captured by coefficients on time dummies $D_{t}$ and interaction terms $D^{*}{ }^{*} D_{E U}$, specifically $\exp \left(\mathrm{Yt}_{\mathrm{t}}\right)$ for NON-EU and $\exp \left(\mathrm{Y}_{\mathrm{t}}+\lambda_{\mathrm{t}}\right)$ for EU15 (left axis). Columns indicate statistical significance levels of interaction terms Dt ${ }^{*} \mathrm{DEU}_{\text {(right }}$ axis).

Figure 9: Jersey deposits, EU15 vs. OECD

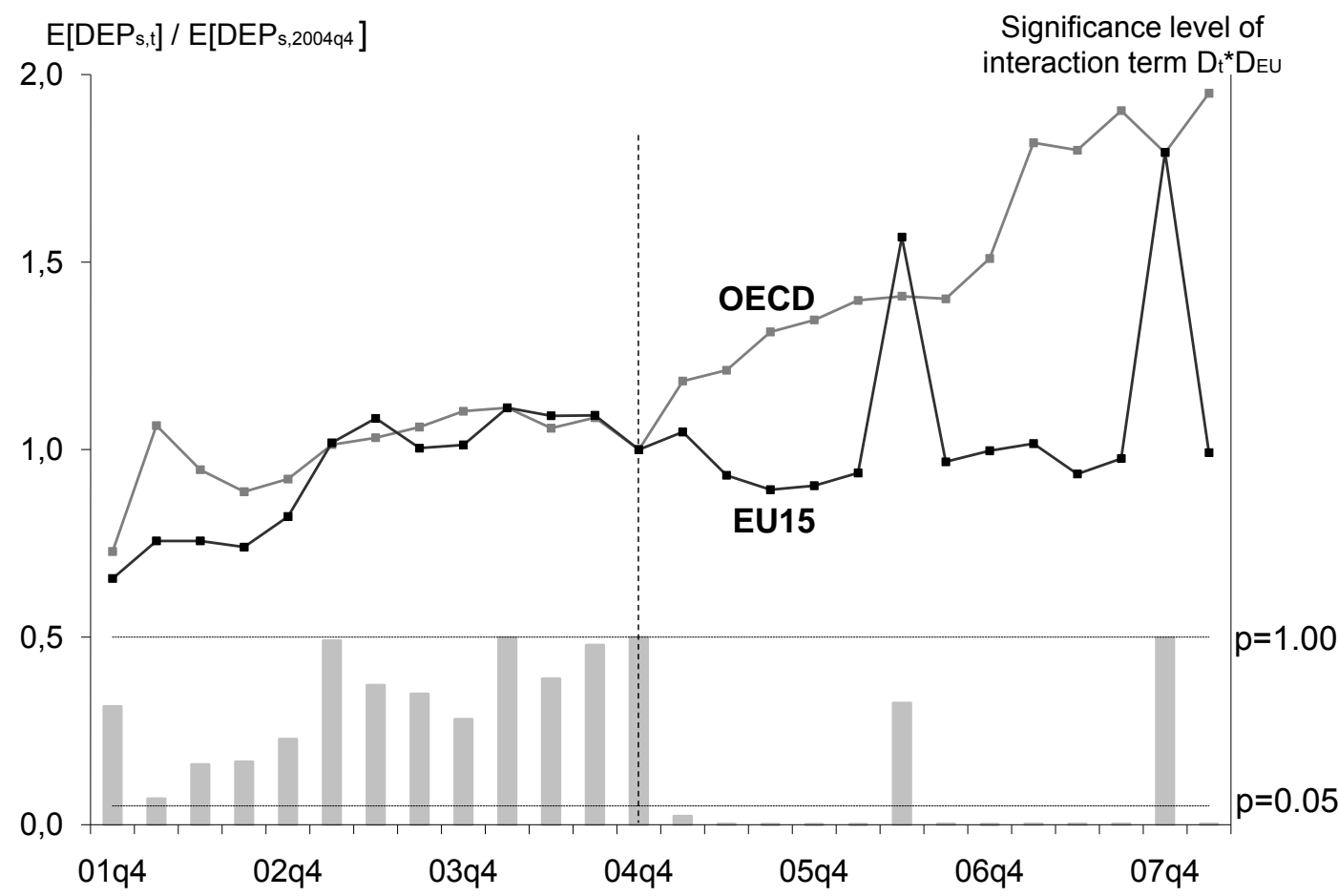

Note: Lines indicate trends in DEPst as captured by coefficients on time dummies $\mathrm{Dt}$ and interaction terms $\mathrm{Dt}^{*} \mathrm{DEU}$, specifically $\exp \left(\mathrm{Yt}_{\mathrm{t}}\right)$ for NON-EU and $\exp \left(\mathrm{y}_{\mathrm{t}}+\lambda_{t}\right)$ for EU15 (left axis). Columns indicate statistical significance levels of interaction terms Dt* ${ }^{*} \mathrm{Eu}$ (right axis). 
Appendix B

NOT FOR PUBLICATION!!!

Panel A

\begin{tabular}{|c|c|c|c|c|c|c|c|c|}
\hline Banking Jur & \multicolumn{4}{|c|}{ Switzerland } & \multicolumn{4}{|c|}{ Switzerland } \\
\hline Treatment & \multicolumn{4}{|c|}{ EU15 } & \multicolumn{4}{|c|}{ NEW10 } \\
\hline Control & \multicolumn{4}{|c|}{ NON-EU } & \multicolumn{4}{|c|}{ NON-EU } \\
\hline \multirow[t]{3}{*}{ Currency } & \multicolumn{4}{|c|}{ ALL } & \multicolumn{4}{|c|}{ ALL } \\
\hline & \multicolumn{2}{|c|}{ Time dummies $(\mathrm{Dt})$} & \multicolumn{2}{|c|}{ Interaction terms $\left(\mathrm{Dt}^{*} \mathrm{EU}\right)$} & \multicolumn{2}{|c|}{ Time dummies (Dt) } & \multicolumn{2}{|c|}{ Interaction terms (Dt*EU) } \\
\hline & coefficient & se & coefficient & se & coefficient & se & coefficient & se \\
\hline $1995 q 4$ & $-0.440^{\star * *}$ & $(0.0819)$ & 0.0944 & $(0.136)$ & $-0.440^{\star * *}$ & $(0.0819)$ & $-0.789^{\star \star \star}$ & $(0.119)$ \\
\hline $1996 q 1$ & $-0.420^{* \star *}$ & $(0.0797)$ & 0.0821 & $(0.137)$ & $-0.420^{\star * *}$ & $(0.0797)$ & $-0.692^{* \star *}$ & $(0.131)$ \\
\hline $1996 q 2$ & $-0.445^{\star * *}$ & $(0.0816)$ & 0.0624 & $(0.139)$ & $-0.445^{\star * \star}$ & $(0.0816)$ & $-0.677^{* * *}$ & $(0.129)$ \\
\hline 1996q3 & $-0.446^{\star * \star}$ & $(0.0784)$ & 0.0690 & $(0.135)$ & $-0.446^{\star * *}$ & $(0.0784)$ & $-0.620^{\star * *}$ & $(0.135)$ \\
\hline $1996 q 4$ & $-0.389^{* * *}$ & $(0.0792)$ & 0.0569 & $(0.136)$ & $-0.389^{* * *}$ & $(0.0792)$ & $-0.595^{\star \star \star}$ & $(0.149)$ \\
\hline $1997 q 1$ & $-0.380^{* * *}$ & (0.0801) & 0.0336 & $(0.137)$ & $-0.380^{\star * *}$ & $(0.0801)$ & $-0.622^{\star \star \star}$ & $(0.161)$ \\
\hline $1997 q 2$ & $-0.408^{* * *}$ & (0.0777) & 0.0371 & $(0.135)$ & $-0.408^{* * *}$ & (0.0778) & $-0.507^{* * *}$ & $(0.164)$ \\
\hline 1997q3 & $-0.408^{* * *}$ & $(0.0741)$ & 0.0776 & $(0.139)$ & $-0.408^{* * *}$ & $(0.0741)$ & $-0.428^{* *}$ & $(0.187)$ \\
\hline $1997 q 4$ & $-0.401^{* * *}$ & $(0.0731)$ & 0.0537 & $(0.134)$ & $-0.401^{* * *}$ & $(0.0731)$ & $-0.408^{* *}$ & $(0.183)$ \\
\hline $1998 q 1$ & $-0.359^{* * *}$ & $(0.0730)$ & 0.0139 & $(0.128)$ & $-0.359^{* \star *}$ & $(0.0730)$ & $-0.450^{\star *}$ & (0.192) \\
\hline $1998 q 2$ & $-0.388^{* * *}$ & $(0.0711)$ & 0.0762 & $(0.132)$ & $-0.388^{* * *}$ & $(0.0711)$ & $-0.411^{* *}$ & $(0.185)$ \\
\hline 1998q3 & $-0.315^{* * *}$ & $(0.0710)$ & 0.0462 & $(0.132)$ & $-0.315^{\star * *}$ & $(0.0710)$ & $-0.402^{* *}$ & $(0.186)$ \\
\hline $1998 q 4$ & $-0.310^{* * *}$ & (0.0705) & 0.0447 & $(0.118)$ & $-0.310^{* * *}$ & $(0.0706)$ & $-0.334^{* *}$ & $(0.155)$ \\
\hline $1999 q 1$ & $-0.203^{* * *}$ & $(0.0685)$ & 0.113 & $(0.118)$ & $-0.203^{* * *}$ & $(0.0685)$ & $-0.256^{* *}$ & $(0.129)$ \\
\hline $1999 q 2$ & $-0.223^{* * *}$ & $(0.0677)$ & 0.111 & $(0.118)$ & $-0.223^{* * *}$ & $(0.0677)$ & $-0.267^{* *}$ & $(0.131)$ \\
\hline $1999 q 3$ & $-0.158^{* *}$ & (0.0707) & 0.0342 & $(0.106)$ & $-0.158^{\star *}$ & (0.0707) & $-0.307^{\star *}$ & $(0.141)$ \\
\hline $1999 q 4$ & $-0.201^{* * *}$ & $(0.0683)$ & 0.0766 & $(0.0958)$ & $-0.201^{* * *}$ & $(0.0683)$ & $-0.235^{\star}$ & $(0.137)$ \\
\hline $2000 q 1$ & $-0.321^{* * *}$ & $(0.0725)$ & 0.176 & $(0.115)$ & $-0.321^{* * *}$ & (0.0725) & -0.184 & $(0.138)$ \\
\hline $2000 q 2$ & $-0.365^{* * *}$ & $(0.0663)$ & 0.107 & $(0.0912)$ & $-0.365^{* * *}$ & $(0.0663)$ & -0.148 & $(0.123)$ \\
\hline $2000 q 3$ & $-0.341^{* * *}$ & $(0.0595)$ & 0.0177 & $(0.0876)$ & $-0.341^{* * *}$ & (0.0595) & -0.0904 & $(0.126)$ \\
\hline $2000 q 4$ & $-0.291^{* * *}$ & $(0.0577)$ & 0.0210 & $(0.0947)$ & $-0.291^{* * *}$ & (0.0577) & -0.0820 & (0.103) \\
\hline $2001 q 1$ & $-0.242^{* * *}$ & $(0.0514)$ & 0.000959 & (0.0896) & $-0.242^{* * *}$ & $(0.0514)$ & -0.00155 & (0.109) \\
\hline $2001 q 2$ & $-0.235^{\star \star *}$ & $(0.0502)$ & -0.0675 & $(0.0908)$ & $-0.235^{\star * *}$ & $(0.0502)$ & -0.00682 & (0.108) \\
\hline $2001 q 3$ & $-0.212^{\star \star *}$ & $(0.0488)$ & -0.0286 & $(0.0886)$ & $-0.212^{\star * *}$ & $(0.0488)$ & -0.0594 & $(0.0981)$ \\
\hline $2001 q 4$ & $-0.222^{\star \star *}$ & $(0.0480)$ & -0.0725 & $(0.0786)$ & $-0.222^{\star * *}$ & $(0.0480)$ & -0.0648 & $(0.0896)$ \\
\hline $2002 q 1$ & $-0.245^{\star \star *}$ & $(0.0478)$ & -0.0691 & $(0.0648)$ & $-0.245^{\star \star \star}$ & $(0.0478)$ & -0.0471 & $(0.0908)$ \\
\hline $2002 q 2$ & $-0.195^{\star \star \star}$ & $(0.0463)$ & -0.0795 & $(0.0687)$ & $-0.195^{\star \star *}$ & $(0.0464)$ & -0.108 & $(0.0752)$ \\
\hline $2002 q 3$ & $-0.196^{\star * *}$ & $(0.0464)$ & -0.0537 & $(0.0734)$ & $-0.196^{* * *}$ & $(0.0465)$ & -0.109 & $(0.0772)$ \\
\hline $2002 q 4$ & $-0.143^{\star * *}$ & $(0.0470)$ & -0.0824 & $(0.0678)$ & $-0.143^{* * *}$ & $(0.0470)$ & -0.0940 & $(0.0734)$ \\
\hline $2003 q 1$ & $-0.157^{* * *}$ & $(0.0434)$ & -0.0330 & $(0.0626)$ & $-0.157^{* * *}$ & $(0.0434)$ & -0.0126 & $(0.0744)$ \\
\hline $2003 q 2$ & $-0.150^{* * *}$ & $(0.0414)$ & -0.0264 & $(0.0621)$ & $-0.150^{* * *}$ & $(0.0415)$ & -0.0406 & $(0.0582)$ \\
\hline $2003 q 3$ & $-0.132^{* * *}$ & $(0.0364)$ & -0.00591 & $(0.0572)$ & $-0.132^{* * *}$ & $(0.0364)$ & -0.0109 & $(0.0552)$ \\
\hline $2003 q 4$ & $-0.110^{* * *}$ & $(0.0390)$ & 0.0214 & $(0.0477)$ & $-0.110^{\star * *}$ & $(0.0390)$ & -0.0364 & $(0.0490)$ \\
\hline $2004 q 1$ & $-0.115^{\star \star *}$ & $(0.0369)$ & 0.0175 & $(0.0495)$ & $-0.115^{\star \star \star}$ & $(0.0369)$ & -0.0170 & $(0.0484)$ \\
\hline $2004 q 2$ & $-0.0972^{* \star *}$ & $(0.0333)$ & 0.0207 & $(0.0438)$ & $-0.0972^{* * *}$ & $(0.0333)$ & -0.0372 & $(0.0438)$ \\
\hline $2004 q 3$ & $-0.0819^{\star *}$ & $(0.0354)$ & 0.0276 & $(0.0482)$ & $-0.0819^{\star *}$ & $(0.0354)$ & -0.0334 & $(0.0424)$ \\
\hline $2004 q 4$ & - & - & - & - & - & - & - & - \\
\hline $2005 q 1$ & -0.0124 & $(0.0261)$ & -0.0323 & $(0.0293)$ & -0.0124 & $(0.0261)$ & 0.0626 & $(0.0414)$ \\
\hline $2005 q 2$ & 0.0208 & $(0.0405)$ & $-0.211^{* * *}$ & $(0.0503)$ & 0.0208 & $(0.0405)$ & -0.0566 & $(0.0471)$ \\
\hline $2005 q 3$ & 0.0663 & $(0.0412)$ & $-0.405^{\star \star *}$ & $(0.0627)$ & 0.0663 & $(0.0412)$ & $-0.145^{\star *}$ & $(0.0579)$ \\
\hline $2005 q 4$ & $0.0959^{* *}$ & $(0.0381)$ & $-0.439^{* * *}$ & $(0.0678)$ & $0.0959^{* *}$ & $(0.0381)$ & $-0.212^{* * *}$ & $(0.0537)$ \\
\hline $2006 q 1$ & $0.136^{\star * *}$ & $(0.0396)$ & $-0.481^{* * *}$ & $(0.0769)$ & $0.136^{* * *}$ & $(0.0396)$ & $-0.153^{* *}$ & $(0.0733)$ \\
\hline $2006 q 2$ & $0.239^{\star \star *}$ & $(0.0447)$ & $-0.533^{\star * *}$ & (0.0896) & $0.239^{\star * *}$ & $(0.0447)$ & -0.102 & $(0.0893)$ \\
\hline $2006 q 3$ & $0.299^{* * *}$ & $(0.0538)$ & $-0.585^{\star * *}$ & (0.0983) & $0.299^{* * *}$ & $(0.0538)$ & -0.0477 & $(0.109)$ \\
\hline $2006 q 4$ & $0.375^{\star * *}$ & $(0.0527)$ & $-0.555^{* * *}$ & $(0.118)$ & $0.375^{\star \star *}$ & $(0.0527)$ & -0.0790 & $(0.104)$ \\
\hline $2007 q 1$ & $0.414^{\star * *}$ & $(0.0568)$ & $-0.559^{* * *}$ & $(0.121)$ & $0.414^{* * *}$ & $(0.0568)$ & -0.130 & $(0.102)$ \\
\hline $2007 q 2$ & $0.456^{\star * *}$ & $(0.0580)$ & $-0.539^{\star * *}$ & $(0.115)$ & $0.456^{\star * *}$ & $(0.0580)$ & -0.0685 & $(0.112)$ \\
\hline $2007 q 3$ & $0.498^{* * *}$ & $(0.0606)$ & $-0.515^{\star \star \star}$ & $(0.116)$ & $0.498^{* * *}$ & $(0.0606)$ & -0.0159 & $(0.142)$ \\
\hline $2007 q 4$ & $0.555^{\star * *}$ & $(0.0618)$ & $-0.502^{* * *}$ & $(0.122)$ & $0.555^{\star * *}$ & $(0.0618)$ & -0.125 & $(0.126)$ \\
\hline $2008 q 1$ & $0.609^{* * *}$ & $(0.0624)$ & $-0.455^{\star \star *}$ & $(0.123)$ & $0.609^{* * *}$ & $(0.0624)$ & -0.0390 & $(0.127)$ \\
\hline Observations & & & & & & & & \\
\hline R.-squared & & & & & & & & \\
\hline
\end{tabular}

Note: Country dummies and constant term not reported. Standard errors are robust to heteroscedasticity and serial correlation 
Panel C

Panel D

\begin{tabular}{|c|c|c|c|c|c|c|c|c|}
\hline \multirow{7}{*}{$\begin{array}{l}\text { Banking Jur } \\
\text { Treatment } \\
\text { Control } \\
\text { Currency } \\
\end{array}$} & \multirow{2}{*}{\multicolumn{4}{|c|}{ Switzerland }} & \multirow{2}{*}{\multicolumn{4}{|c|}{ Switzerland }} \\
\hline & & & & & & & & \\
\hline & \multicolumn{4}{|c|}{ EU15 } & \multicolumn{4}{|c|}{ EU15 } \\
\hline & \multicolumn{4}{|c|}{ OECD } & \multicolumn{4}{|c|}{ NON-EU } \\
\hline & \multicolumn{4}{|c|}{ ALL } & \multicolumn{4}{|c|}{ EURO } \\
\hline & \multicolumn{2}{|c|}{ Time dummies $(\mathrm{Dt})$} & \multicolumn{2}{|c|}{ Interaction terms $\left(\mathrm{Dt}^{*} \mathrm{EU}\right)$} & \multicolumn{2}{|c|}{ Time dummies $(\mathrm{Dt})$} & \multicolumn{2}{|c|}{ Interaction terms $\left(\mathrm{Dt}^{*} \mathrm{EU}\right.$} \\
\hline & coefficient & se & coefficient & se & coefficient & se & coefficient & se \\
\hline $1995 q 4$ & $-0.529^{\star \star *}$ & $(0.128)$ & 0.184 & $(0.172)$ & $-0.667^{\star * \star}$ & $(0.107)$ & 0.00956 & $(0.172)$ \\
\hline $1996 q 1$ & $-0.495^{\star \star \star}$ & $(0.107)$ & 0.157 & $(0.158)$ & $-0.692^{* \star *}$ & $(0.107)$ & -0.0196 & $(0.173)$ \\
\hline 1996q2 & $-0.411^{\star * *}$ & $(0.140)$ & 0.0281 & $(0.183)$ & $-0.680^{* * *}$ & $(0.103)$ & -0.0919 & $(0.175)$ \\
\hline $1996 q 3$ & $-0.461^{* * *}$ & $(0.149)$ & 0.0847 & $(0.189)$ & $-0.762^{\star * *}$ & $(0.104)$ & -0.0440 & $(0.179)$ \\
\hline $1996 q 4$ & $-0.435^{\star \star \star}$ & $(0.0940)$ & 0.102 & $(0.149)$ & $-0.832^{\star \star *}$ & $(0.0988)$ & 0.0647 & $(0.170)$ \\
\hline $1997 q 1$ & $-0.461^{* * *}$ & $(0.0799)$ & 0.115 & $(0.142)$ & $-0.784^{* \star *}$ & $(0.0996)$ & -0.0316 & $(0.176)$ \\
\hline 1997q2 & $-0.438^{* \star *}$ & $(0.109)$ & 0.0666 & $(0.159)$ & $-0.863^{\star \star *}$ & $(0.0960)$ & -0.0224 & $(0.182)$ \\
\hline $1997 q 3$ & $-0.409^{\star * \star}$ & $(0.121)$ & 0.0789 & $(0.173)$ & $-0.912^{\star \star \star}$ & $(0.0926)$ & 0.00652 & $(0.188)$ \\
\hline $1997 q 4$ & $-0.385^{\star * *}$ & $(0.114)$ & 0.0376 & $(0.164)$ & $-0.911^{* * *}$ & $(0.0935)$ & -0.0432 & $(0.183)$ \\
\hline $1998 q 1$ & $-0.361^{* * *}$ & $(0.126)$ & 0.0157 & $(0.168)$ & $-0.899^{\star * *}$ & $(0.0882)$ & -0.0523 & (0.172) \\
\hline 1998q2 & $-0.317^{* * *}$ & $(0.0887)$ & 0.00598 & $(0.147)$ & $-0.951^{* * *}$ & $(0.0902)$ & -0.00904 & $(0.169)$ \\
\hline $1998 q 3$ & $-0.277^{\star * *}$ & $(0.0790)$ & 0.00788 & $(0.142)$ & $-0.888^{* * *}$ & $(0.0900)$ & -0.0134 & $(0.170)$ \\
\hline $1998 q 4$ & $-0.271^{* * *}$ & $(0.0845)$ & 0.00545 & $(0.131)$ & $-0.742^{* * *}$ & $(0.0893)$ & 0.0843 & $(0.141)$ \\
\hline $1999 q 1$ & -0.104 & $(0.0997)$ & 0.0141 & $(0.143)$ & $-0.734^{\star \star *}$ & $(0.0865)$ & 0.141 & $(0.139)$ \\
\hline 1999q2 & $-0.169^{*}$ & $(0.0916)$ & 0.0572 & $(0.137)$ & $-0.702^{\star \star \star}$ & $(0.0878)$ & 0.0831 & $(0.143)$ \\
\hline $1999 q 3$ & $-0.176^{\star * *}$ & $(0.0619)$ & 0.0525 & $(0.103)$ & $-0.657^{\star * *}$ & $(0.0859)$ & 0.0822 & $(0.128)$ \\
\hline $1999 q 4$ & $-0.171^{\star *}$ & $(0.0679)$ & 0.0469 & $(0.0981)$ & $-0.651^{* * *}$ & $(0.0846)$ & 0.152 & $(0.116)$ \\
\hline $2000 q 1$ & $-0.164^{* *}$ & $(0.0670)$ & 0.0192 & $(0.116)$ & $-0.716^{* * *}$ & $(0.0890)$ & 0.141 & $(0.125)$ \\
\hline 2000q2 & $-0.157^{\star *}$ & $(0.0593)$ & -0.101 & $(0.0887)$ & $-0.779^{* * *}$ & $(0.0833)$ & $0.232^{*}$ & $(0.125)$ \\
\hline $2000 q 3$ & $-0.204^{* * *}$ & $(0.0605)$ & -0.119 & $(0.0908)$ & $-0.775^{\star * \star}$ & $(0.0806)$ & 0.156 & $(0.115)$ \\
\hline $2000 q 4$ & $-0.163^{* *}$ & $(0.0704)$ & -0.107 & $(0.106)$ & $-0.704^{\star * *}$ & $(0.0768)$ & $0.199^{*}$ & $(0.115)$ \\
\hline $2001 q 1$ & $-0.161^{* *}$ & $(0.0632)$ & -0.0794 & $(0.0999)$ & $-0.604^{* * *}$ & $(0.0773)$ & 0.123 & $(0.115)$ \\
\hline 2001q2 & $-0.128^{*}$ & $(0.0706)$ & -0.175 & $(0.107)$ & $-0.572^{\star * \star}$ & $(0.0708)$ & 0.0375 & $(0.111)$ \\
\hline 2001q3 & $-0.135^{\star *}$ & $(0.0544)$ & -0.106 & $(0.0950)$ & $-0.516^{* * *}$ & $(0.0783)$ & 0.111 & $(0.112)$ \\
\hline $2001 q 4$ & $-0.149^{* *}$ & $(0.0671)$ & -0.146 & $(0.0938)$ & $-0.461^{* * *}$ & $(0.0762)$ & 0.00222 & $(0.108)$ \\
\hline $2002 q 1$ & $-0.157^{\star *}$ & $(0.0619)$ & $-0.157^{*}$ & $(0.0772)$ & $-0.483^{\star \star *}$ & $(0.0725)$ & 0.0125 & $(0.103)$ \\
\hline $2002 q 2$ & $-0.113^{*}$ & $(0.0566)$ & $-0.162^{\star \star}$ & $(0.0779)$ & $-0.347^{\star \star *}$ & $(0.0703)$ & 0.00230 & $(0.0998)$ \\
\hline $2002 q 3$ & $-0.136^{\star * *}$ & $(0.0480)$ & -0.114 & $(0.0768)$ & $-0.277^{\star * *}$ & $(0.0667)$ & -0.0513 & $(0.0939)$ \\
\hline $2002 q 4$ & -0.0804 & $(0.0925)$ & -0.145 & $(0.106)$ & $-0.291^{* * *}$ & $(0.0626)$ & 0.00178 & $(0.0919)$ \\
\hline $2003 q 1$ & -0.0855 & $(0.0872)$ & -0.105 & $(0.0993)$ & $-0.189^{* * *}$ & $(0.0563)$ & -0.0181 & $(0.0811)$ \\
\hline $2003 q 2$ & -0.0594 & $(0.0865)$ & -0.117 & $(0.0992)$ & $-0.164^{\star \star *}$ & $(0.0541)$ & -0.0206 & $(0.0785)$ \\
\hline $2003 q 3$ & $-0.113^{*}$ & $(0.0623)$ & -0.0253 & $(0.0778)$ & $-0.146^{\star \star *}$ & $(0.0543)$ & 0.00980 & $(0.0801)$ \\
\hline $2003 q 4$ & $-0.0972^{*}$ & $(0.0560)$ & 0.00872 & $(0.0630)$ & $-0.166^{\star \star \star}$ & $(0.0478)$ & 0.0582 & $(0.0641)$ \\
\hline $2004 q 1$ & -0.0706 & $(0.0441)$ & -0.0264 & $(0.0562)$ & $-0.0880^{*}$ & $(0.0496)$ & -0.0121 & $(0.0602)$ \\
\hline $2004 q 2$ & $-0.0672^{*}$ & $(0.0337)$ & -0.00934 & $(0.0451)$ & -0.0389 & $(0.0483)$ & -0.0133 & $(0.0605)$ \\
\hline $2004 q 3$ & $-0.0969^{*}$ & $(0.0501)$ & 0.0426 & $(0.0607)$ & $-0.0667^{*}$ & (0.0401) & 0.0150 & $(0.0539)$ \\
\hline $2004 q 4$ & - & - & - & - & - & - & - & - \\
\hline $2005 q 1$ & 0.00688 & $(0.0263)$ & $-0.0516^{\star}$ & $(0.0298)$ & 0.0344 & $(0.0343)$ & -0.0293 & $(0.0387)$ \\
\hline $2005 q 2$ & 0.0301 & $(0.0185)$ & $-0.220^{\star \star \star}$ & $(0.0365)$ & $0.109^{* *}$ & $(0.0509)$ & $-0.278^{\star * \star}$ & $(0.0590)$ \\
\hline $2005 q 3$ & 0.112 & $(0.0697)$ & $-0.451^{* * *}$ & $(0.0857)$ & 0.0792 & $(0.0543)$ & $-0.440^{\star * *}$ & $(0.0729)$ \\
\hline $2005 q 4$ & $0.120^{\star * *}$ & $(0.0366)$ & $-0.463^{\star * *}$ & $(0.0695)$ & $0.144^{* * *}$ & $(0.0503)$ & $-0.515^{\star * *}$ & $(0.0774)$ \\
\hline $2006 q 1$ & $0.118^{* * *}$ & $(0.0232)$ & $-0.464^{\star * *}$ & $(0.0732)$ & $0.210^{* * *}$ & $(0.0505)$ & $-0.583^{* * *}$ & $(0.0829)$ \\
\hline 2006q2 & $0.272^{\star * *}$ & $(0.0575)$ & $-0.566^{\star * *}$ & $(0.1000)$ & $0.311^{* * *}$ & $(0.0527)$ & $-0.574^{\star \star \star}$ & $(0.0885)$ \\
\hline $2006 q 3$ & $0.309^{\star \star *}$ & $(0.0620)$ & $-0.595^{\star \star *}$ & $(0.107)$ & $0.294^{* * *}$ & $(0.0606)$ & $-0.544^{* * *}$ & $(0.102)$ \\
\hline $2006 q 4$ & $0.320^{\star * *}$ & $(0.0641)$ & $-0.501^{* * *}$ & $(0.128)$ & $0.357^{* * *}$ & $(0.0573)$ & $-0.513^{* * *}$ & $(0.119)$ \\
\hline $2007 q 1$ & $0.392^{* * *}$ & $(0.0651)$ & $-0.537^{\star * *}$ & $(0.130)$ & $0.379^{* * *}$ & $(0.0660)$ & $-0.472^{* * *}$ & $(0.131)$ \\
\hline $2007 q 2$ & $0.373^{\star \star \star}$ & $(0.0582)$ & $-0.456^{\star \star \star}$ & $(0.120)$ & $0.416^{\star * *}$ & $(0.0670)$ & $-0.462^{* \star *}$ & $(0.120)$ \\
\hline $2007 q 3$ & $0.426^{* * *}$ & $(0.0588)$ & $-0.442^{\star * *}$ & $(0.120)$ & $0.525^{\star * *}$ & $(0.0649)$ & $-0.470^{* * *}$ & $(0.111)$ \\
\hline $2007 q 4$ & $0.499^{* * *}$ & $(0.0789)$ & $-0.446^{* * *}$ & $(0.136)$ & $0.624^{* * *}$ & $(0.0693)$ & $-0.447^{* * *}$ & $(0.129)$ \\
\hline $2008 q 1$ & $0.510^{\star * *}$ & $(0.0710)$ & $-0.356^{\star *}$ & $(0.132)$ & $0.770^{\star * *}$ & $(0.0656)$ & $-0.486^{\star * *}$ & $(0.123)$ \\
\hline Observations & \multicolumn{4}{|c|}{1250} & \multicolumn{4}{|c|}{7674} \\
\hline R.-squared & & & & & & & & \\
\hline
\end{tabular}

Note: Country dummies and constant term not reported. Standard errors are robust to heteroscedasticity and serial correlation 
Panel E

Panel $F$

\begin{tabular}{|c|c|c|c|c|c|c|c|c|}
\hline \multirow{6}{*}{$\begin{array}{l}\text { Banking Jur } \\
\text { Treatment } \\
\text { Control } \\
\text { Currency } \\
\end{array}$} & & \multicolumn{4}{|c|}{ Switzerland } \\
\hline & \multirow{2}{*}{\multicolumn{4}{|c|}{$\begin{array}{c}\text { EU15 } \\
\text { NON-EU }\end{array}$}} & \multicolumn{4}{|c|}{ EU15 } \\
\hline & & & & & \multicolumn{4}{|c|}{ NON-EU } \\
\hline & \multirow{2}{*}{\multicolumn{4}{|c|}{$\begin{array}{l}\text { USD } \\
\text { Interaction terms }\left(\mathrm{Dt}^{*} \mathrm{EU}\right)\end{array}$}} & \multicolumn{4}{|c|}{$\mathrm{CHF}$} \\
\hline & & & & & \multicolumn{2}{|c|}{ Time dummies $(\mathrm{Dt})$} & \multicolumn{2}{|c|}{ Interaction terms $\left(\mathrm{Dt}^{*} \mathrm{EU}\right)$} \\
\hline & coefficient & se & coefficient & se & coefficient & se & coefficient & se \\
\hline $1995 q 4$ & $-0.396^{\star * *}$ & $(0.0784)$ & $0.289^{*}$ & $(0.162)$ & -0.0263 & $(0.0959)$ & -0.0415 & $(0.198)$ \\
\hline $1996 q 1$ & $-0.354^{* \star *}$ & $(0.0778)$ & $0.302^{*}$ & $(0.158)$ & -0.102 & $(0.0943)$ & 0.0190 & $(0.191)$ \\
\hline 1996q2 & $-0.363^{\star * *}$ & $(0.0769)$ & $0.304^{*}$ & $(0.156)$ & -0.114 & $(0.0926)$ & -0.0487 & $(0.187)$ \\
\hline $1996 q 3$ & $-0.316^{* * *}$ & $(0.0729)$ & $0.299^{* *}$ & $(0.146)$ & $-0.186^{\star *}$ & $(0.0876)$ & -0.0288 & $(0.184)$ \\
\hline $1996 q 4$ & $-0.252^{\star * *}$ & $(0.0737)$ & $0.275^{*}$ & $(0.150)$ & $-0.192^{\star *}$ & $(0.0825)$ & -0.0203 & $(0.178)$ \\
\hline $1997 q 1$ & $-0.267^{\star \star *}$ & $(0.0756)$ & $0.285^{*}$ & $(0.160)$ & $-0.177^{* *}$ & $(0.0858)$ & 0.0142 & $(0.183)$ \\
\hline $1997 q 2$ & $-0.300^{* * *}$ & $(0.0749)$ & $0.333^{* *}$ & $(0.150)$ & $-0.182^{* *}$ & $(0.0807)$ & -0.0180 & $(0.187)$ \\
\hline $1997 q 3$ & $-0.268^{* * *}$ & $(0.0743)$ & $0.362^{* *}$ & (0.161) & $-0.273^{\star * *}$ & $(0.0864)$ & 0.0724 & $(0.184)$ \\
\hline $1997 q 4$ & $-0.246^{\star * *}$ & $(0.0760)$ & $0.352^{* *}$ & $(0.156)$ & $-0.336^{\star * *}$ & $(0.0812)$ & 0.116 & $(0.195)$ \\
\hline $1998 q 1$ & $-0.215^{\star * *}$ & $(0.0757)$ & $0.340^{* *}$ & (0.153) & $-0.316^{\star * *}$ & $(0.0825)$ & 0.0518 & $(0.185)$ \\
\hline 1998q2 & $-0.194^{* * *}$ & $(0.0715)$ & $0.353^{* *}$ & $(0.149)$ & $-0.289^{\star * *}$ & $(0.0803)$ & 0.106 & $(0.231)$ \\
\hline $1998 q 3$ & $-0.135^{\star}$ & $(0.0748)$ & $0.319^{* *}$ & $(0.157)$ & $-0.171^{\star *}$ & $(0.0844)$ & 0.0724 & $(0.224)$ \\
\hline $1998 q 4$ & $-0.130^{*}$ & $(0.0757)$ & $0.264^{*}$ & (0.155) & $-0.268^{* \star *}$ & $(0.0772)$ & 0.142 & $(0.194)$ \\
\hline 1999q1 & -0.0596 & $(0.0795)$ & $0.330^{* *}$ & $(0.158)$ & 0.0997 & (0.0661) & 0.221 & $(0.175)$ \\
\hline $1999 q 2$ & -0.0752 & $(0.0767)$ & $0.270^{*}$ & $(0.159)$ & 0.0365 & $(0.0637)$ & 0.225 & $(0.182)$ \\
\hline $1999 q 3$ & -0.0531 & $(0.0775)$ & $0.264^{*}$ & $(0.138)$ & $0.121^{*}$ & $(0.0618)$ & 0.0978 & $(0.115)$ \\
\hline $1999 q 4$ & -0.0841 & $(0.0804)$ & $0.263^{* *}$ & $(0.132)$ & $0.123^{*}$ & $(0.0688)$ & 0.0518 & $(0.190)$ \\
\hline $2000 q 1$ & $-0.143^{*}$ & $(0.0812)$ & $0.314^{\star * *}$ & $(0.121)$ & -0.0468 & (0.0731) & 0.233 & $(0.232)$ \\
\hline $2000 q 2$ & $-0.156^{\star *}$ & $(0.0726)$ & $0.273^{\star *}$ & $(0.113)$ & $-0.279^{\star \star \star}$ & $(0.0650)$ & 0.127 & $(0.0968)$ \\
\hline $2000 q 3$ & -0.0963 & $(0.0697)$ & 0.182 & $(0.112)$ & $-0.288^{* \star *}$ & $(0.0675)$ & 0.0348 & $(0.0993)$ \\
\hline $2000 q 4$ & -0.0942 & $(0.0644)$ & 0.181 & $(0.122)$ & $-0.230^{\star \star \star}$ & $(0.0681)$ & 0.0515 & $(0.103)$ \\
\hline $2001 q 1$ & -0.0679 & $(0.0646)$ & $0.227^{* *}$ & $(0.112)$ & $-0.143^{\star *}$ & $(0.0565)$ & -0.0489 & $(0.100)$ \\
\hline $2001 q 2$ & -0.0899 & $(0.0580)$ & 0.180 & $(0.116)$ & $-0.144^{\star *}$ & $(0.0643)$ & $-0.196^{\star *}$ & $(0.0884)$ \\
\hline $2001 q 3$ & -0.0878 & $(0.0595)$ & 0.146 & $(0.115)$ & -0.0756 & $(0.0587)$ & -0.148 & $(0.0951)$ \\
\hline $2001 q 4$ & -0.0622 & $(0.0545)$ & 0.0324 & $(0.0947)$ & $-0.140^{* * *}$ & $(0.0528)$ & -0.128 & $(0.0870)$ \\
\hline $2002 q 1$ & $-0.111^{\star *}$ & $(0.0553)$ & 0.00387 & $(0.0897)$ & $-0.181^{\star \star \star}$ & $(0.0572)$ & -0.0684 & $(0.0741)$ \\
\hline $2002 q 2$ & -0.0935 & $(0.0568)$ & -0.0228 & $(0.0806)$ & -0.0552 & $(0.0502)$ & $-0.201^{* * *}$ & $(0.0764)$ \\
\hline $2002 q^{3}$ & -0.0874 & $(0.0538)$ & 0.0209 & $(0.0871)$ & $-0.113^{\star *}$ & $(0.0436)$ & $-0.181^{* *}$ & $(0.0730)$ \\
\hline $2002 q 4$ & -0.0640 & $(0.0550)$ & -0.0714 & $(0.0770)$ & $-0.0719^{*}$ & $(0.0414)$ & -0.115 & $(0.0793)$ \\
\hline $2003 q 1$ & $-0.166^{* * *}$ & $(0.0525)$ & 0.0287 & $(0.0746)$ & $-0.0704^{*}$ & $(0.0379)$ & $-0.129^{\star *}$ & $(0.0631)$ \\
\hline $2003 q 2$ & $-0.144^{* * *}$ & $(0.0496)$ & 0.0294 & $(0.0713)$ & -0.0471 & $(0.0377)$ & $-0.151^{\star *}$ & $(0.0615)$ \\
\hline $2003 q^{3}$ & $-0.167^{* \star *}$ & $(0.0483)$ & 0.0520 & $(0.0685)$ & $-0.0840^{* *}$ & $(0.0371)$ & -0.0905 & $(0.0619)$ \\
\hline $2003 q 4$ & $-0.125^{\star \star}$ & $(0.0511)$ & 0.0861 & $(0.0617)$ & $-0.0715^{\star *}$ & $(0.0343)$ & -0.0231 & $(0.0460)$ \\
\hline $2004 q 1$ & $-0.120^{* *}$ & $(0.0461)$ & 0.0395 & $(0.0633)$ & $-0.0553^{*}$ & $(0.0296)$ & -0.0720 & $(0.0749)$ \\
\hline $2004 q 2$ & $-0.110^{* * *}$ & $(0.0411)$ & 0.0101 & $(0.0540)$ & $-0.0795^{\star * *}$ & $(0.0270)$ & -0.0479 & $(0.0564)$ \\
\hline $2004 q 3$ & $-0.0740^{*}$ & $(0.0387)$ & 0.000610 & $(0.0525)$ & $-0.108^{* * *}$ & $(0.0319)$ & 0.0449 & $(0.0870)$ \\
\hline $2004 q 4$ & - & - & - & - & - & - & - & - \\
\hline $2005 q 1$ & -0.0247 & $(0.0339)$ & -0.0924 & $(0.0562)$ & -0.0150 & $(0.0263)$ & -0.0557 & $(0.0647)$ \\
\hline $2005 q 2$ & -0.00274 & $(0.0479)$ & $-0.223^{\star \star *}$ & $(0.0700)$ & -0.0195 & $(0.0288)$ & -0.119 & $(0.0738)$ \\
\hline $2005 q 3$ & 0.0466 & $(0.0486)$ & $-0.412^{* \star *}$ & $(0.0830)$ & 0.0155 & (0.0331) & $-0.230^{* * *}$ & $(0.0623)$ \\
\hline $2005 q 4$ & $0.0968^{* *}$ & $(0.0464)$ & $-0.517^{* * *}$ & $(0.0916)$ & 0.00366 & $(0.0313)$ & $-0.187^{\star * *}$ & $(0.0610)$ \\
\hline $2006 q 1$ & $0.118^{\star *}$ & $(0.0483)$ & $-0.545^{\star * *}$ & $(0.110)$ & 0.0288 & $(0.0359)$ & $-0.248^{\star * *}$ & $(0.0722)$ \\
\hline $2006 q 2$ & $0.220^{* * *}$ & $(0.0498)$ & $-0.665^{\star \star \star}$ & $(0.129)$ & $0.0846^{* *}$ & $(0.0410)$ & $-0.251^{* * *}$ & $(0.0798)$ \\
\hline $2006 q 3$ & $0.303^{\star * *}$ & $(0.0575)$ & $-0.726^{\star \star *}$ & $(0.127)$ & $0.0833^{*}$ & $(0.0462)$ & $-0.298^{* * *}$ & $(0.0724)$ \\
\hline $2006 q 4$ & $0.382^{\star * *}$ & $(0.0599)$ & $-0.706^{\star \star \star}$ & $(0.155)$ & $0.0992^{* *}$ & $(0.0454)$ & $-0.246^{\star \star \star}$ & $(0.0868)$ \\
\hline $2007 q 1$ & $0.440^{* * *}$ & $(0.0592)$ & $-0.736^{* * *}$ & $(0.148)$ & 0.0790 & $(0.0507)$ & $-0.179^{*}$ & $(0.0957)$ \\
\hline $2007 q 2$ & $0.473^{\star * *}$ & $(0.0609)$ & $-0.695^{\star \star *}$ & $(0.141)$ & $0.150^{\star * *}$ & $(0.0533)$ & $-0.226^{\star *}$ & $(0.109)$ \\
\hline $2007 q 3$ & $0.492^{* * *}$ & $(0.0650)$ & $-0.607^{\star * *}$ & $(0.145)$ & $0.140^{* * *}$ & $(0.0508)$ & $-0.205^{\star}$ & $(0.112)$ \\
\hline $2007 q 4$ & $0.498^{\star * *}$ & $(0.0673)$ & $-0.644^{* * *}$ & $(0.140)$ & $0.179^{\star * *}$ & $(0.0505)$ & -0.172 & $(0.125)$ \\
\hline $2008 q 1$ & $0.511^{* * *}$ & $(0.0680)$ & $-0.544^{* * *}$ & $(0.154)$ & $0.360^{* * *}$ & $(0.0573)$ & $-0.236^{\star *}$ & $(0.114)$ \\
\hline Observations & \multicolumn{4}{|c|}{8621} & \multicolumn{4}{|c|}{7143} \\
\hline R.-squared & \multicolumn{4}{|c|}{0.957} & & & & \\
\hline
\end{tabular}

Note: Country dummies and constant term not reported. Standard errors are robust to heteroscedasticity and serial correlation 
Panel G

Panel H

\begin{tabular}{|c|c|c|c|c|c|c|c|c|}
\hline \multirow{6}{*}{$\begin{array}{l}\text { Banking Jur } \\
\text { Treatment } \\
\text { Control } \\
\text { Currency } \\
\end{array}$} & \multirow{2}{*}{\multicolumn{4}{|c|}{ Switzerland }} & \multirow{2}{*}{\multicolumn{4}{|c|}{ Switzerland }} \\
\hline & & & & & & & & \\
\hline & \multicolumn{4}{|c|}{ EU15 } & \multicolumn{4}{|c|}{ EU15 } \\
\hline & \multicolumn{4}{|c|}{ NON-EU } & \multicolumn{4}{|c|}{ NON-OFC } \\
\hline & \multicolumn{4}{|c|}{ GBP } & \multicolumn{4}{|c|}{ ALL } \\
\hline & \multicolumn{2}{|c|}{ Time dummies $(\mathrm{Dt})$} & \multicolumn{2}{|c|}{ Interaction terms $\left(\mathrm{Dt}^{\star} \mathrm{EU}\right)$} & \multicolumn{2}{|c|}{ Time dummies $(\mathrm{Dt})$} & \multicolumn{2}{|c|}{ Interaction terms $\left(\mathrm{Dt}^{*} \mathrm{EU}\right)$} \\
\hline & coefficient & se & coefficient & se & coefficient & se & coefficient & se \\
\hline $1995 q 4$ & $-0.658^{\star \star \star}$ & $(0.107)$ & 0.0332 & $(0.158)$ & $-0.334^{* * *}$ & $(0.0849)$ & -0.0112 & $(0.138)$ \\
\hline 1996q1 & $-0.684^{* * *}$ & $(0.110)$ & 0.0129 & $(0.167)$ & $-0.319^{* * *}$ & $(0.0797)$ & -0.0190 & $(0.137)$ \\
\hline 1996q2 & $-0.635^{\star * *}$ & $(0.108)$ & -0.0646 & $(0.169)$ & $-0.350^{* * *}$ & $(0.0836)$ & -0.0328 & $(0.140)$ \\
\hline 1996q3 & $-0.654^{* * *}$ & $(0.103)$ & -0.110 & $(0.138)$ & $-0.366^{\star * *}$ & $(0.0810)$ & -0.0111 & $(0.137)$ \\
\hline $1996 q 4$ & $-0.585^{\star * *}$ & $(0.116)$ & 0.0605 & $(0.145)$ & $-0.314^{\star \star \star}$ & $(0.0832)$ & -0.0181 & $(0.138)$ \\
\hline $1997 q 1$ & $-0.602^{* * *}$ & $(0.110)$ & 0.0763 & $(0.132)$ & $-0.277^{* * *}$ & $(0.0815)$ & -0.0691 & $(0.138)$ \\
\hline $1997 q 2$ & $-0.584^{* * *}$ & $(0.105)$ & 0.0125 & $(0.149)$ & $-0.312^{* * *}$ & $(0.0785)$ & -0.0592 & $(0.136)$ \\
\hline $1997 q 3$ & $-0.530^{\star \star *}$ & $(0.0982)$ & 0.0516 & $(0.157)$ & $-0.291^{* * *}$ & $(0.0740)$ & -0.0393 & $(0.139)$ \\
\hline $1997 q 4$ & $-0.536^{\star * *}$ & $(0.106)$ & 0.0352 & $(0.146)$ & $-0.288^{* * *}$ & $(0.0734)$ & -0.0590 & $(0.134)$ \\
\hline 1998q1 & $-0.469^{* * *}$ & $(0.104)$ & -0.0464 & $(0.140)$ & $-0.265^{\star * *}$ & $(0.0761)$ & -0.0799 & $(0.130)$ \\
\hline 1998q2 & $-0.448^{* * *}$ & $(0.0962)$ & -0.114 & $(0.142)$ & $-0.299^{\star * *}$ & $(0.0735)$ & -0.0125 & $(0.133)$ \\
\hline $1998 q 3$ & $-0.431^{* * *}$ & $(0.0976)$ & -0.0848 & $(0.149)$ & $-0.237^{\star * *}$ & $(0.0735)$ & -0.0324 & $(0.134)$ \\
\hline $1998 q 4$ & $-0.525^{\star \star *}$ & $(0.100)$ & -0.0322 & $(0.153)$ & $-0.219^{\star \star \star}$ & $(0.0716)$ & -0.0467 & $(0.119)$ \\
\hline $1999 q 1$ & $-0.497^{\star \star \star}$ & $(0.0977)$ & 0.0403 & $(0.178)$ & $-0.123^{*}$ & $(0.0681)$ & 0.0330 & $(0.118)$ \\
\hline 1999q2 & $-0.576^{* * *}$ & $(0.0959)$ & 0.0788 & $(0.170)$ & $-0.156^{* *}$ & $(0.0661)$ & 0.0439 & $(0.117)$ \\
\hline 1999q3 & $-0.609^{* * *}$ & $(0.0947)$ & 0.203 & $(0.173)$ & -0.0697 & (0.0695) & -0.0539 & $(0.105)$ \\
\hline $1999 q 4$ & $-0.645^{\star \star *}$ & $(0.101)$ & 0.170 & $(0.168)$ & $-0.109^{*}$ & $(0.0625)$ & -0.0148 & $(0.0919)$ \\
\hline $2000 q 1$ & $-0.639^{\star \star *}$ & $(0.109)$ & 0.0616 & $(0.146)$ & $-0.244^{\star \star *}$ & $(0.0697)$ & 0.0991 & $(0.114)$ \\
\hline $2000 q 2$ & $-0.548^{\star \star \star}$ & $(0.0893)$ & -0.0912 & $(0.120)$ & $-0.306^{\star * *}$ & $(0.0643)$ & 0.0481 & $(0.0898)$ \\
\hline $2000 q 3$ & $-0.552^{\star * *}$ & $(0.0937)$ & -0.175 & $(0.132)$ & $-0.295^{\star * *}$ & $(0.0591)$ & -0.0283 & $(0.0874)$ \\
\hline $2000 q 4$ & $-0.524^{* * *}$ & $(0.0872)$ & -0.133 & $(0.134)$ & $-0.246^{\star * *}$ & $(0.0609)$ & -0.0238 & $(0.0968)$ \\
\hline 2001q1 & $-0.541^{* * *}$ & $(0.0816)$ & -0.121 & $(0.126)$ & $-0.185^{* * *}$ & $(0.0531)$ & -0.0556 & $(0.0906)$ \\
\hline 2001q2 & $-0.532^{\star * *}$ & $(0.0836)$ & -0.142 & $(0.127)$ & $-0.179^{\star * *}$ & $(0.0515)$ & -0.124 & $(0.0916)$ \\
\hline $2001 q 3$ & $-0.521^{* * *}$ & $(0.0791)$ & -0.134 & $(0.113)$ & $-0.173^{\star \star \star}$ & $(0.0511)$ & -0.0677 & $(0.0900)$ \\
\hline $2001 q 4$ & $-0.492^{\star * *}$ & $(0.0805)$ & -0.168 & $(0.136)$ & $-0.202^{\star \star \star}$ & $(0.0520)$ & -0.0920 & $(0.0812)$ \\
\hline $2002 q 1$ & $-0.548^{* * *}$ & $(0.0769)$ & -0.130 & $(0.104)$ & $-0.226^{* * *}$ & $(0.0516)$ & -0.0880 & $(0.0677)$ \\
\hline $2002 q 2$ & $-0.498^{* * *}$ & $(0.0762)$ & -0.129 & $(0.120)$ & $-0.189^{* * *}$ & $(0.0492)$ & -0.0858 & $(0.0707)$ \\
\hline $2002 q 3$ & $-0.508^{\star * *}$ & $(0.0767)$ & -0.124 & $(0.113)$ & $-0.173^{\star * \star}$ & (0.0499) & -0.0771 & $(0.0757)$ \\
\hline $2002 q 4$ & $-0.468^{\star * *}$ & $(0.0735)$ & -0.0246 & $(0.114)$ & $-0.118^{\star *}$ & $(0.0523)$ & -0.108 & $(0.0716)$ \\
\hline $2003 q 1$ & $-0.437^{\star * *}$ & $(0.0736)$ & 0.0184 & $(0.113)$ & $-0.130^{\star \star \star}$ & $(0.0477)$ & -0.0599 & $(0.0657)$ \\
\hline $2003 q 2$ & $-0.406^{\star * *}$ & $(0.0730)$ & -0.0419 & $(0.104)$ & $-0.134^{* * *}$ & $(0.0459)$ & -0.0427 & $(0.0652)$ \\
\hline $2003 q 3$ & $-0.336^{\star * *}$ & $(0.0728)$ & 0.0229 & $(0.110)$ & $-0.117^{* * *}$ & $(0.0398)$ & -0.0213 & $(0.0594)$ \\
\hline $2003 q 4$ & $-0.350^{* * *}$ & $(0.0683)$ & 0.0656 & $(0.0883)$ & $-0.0975^{\star *}$ & $(0.0417)$ & 0.00907 & $(0.0499)$ \\
\hline $2004 q 1$ & $-0.230^{* * *}$ & $(0.0638)$ & 0.0149 & $(0.0781)$ & $-0.111^{* * *}$ & $(0.0405)$ & 0.0143 & $(0.0523)$ \\
\hline $2004 q 2$ & $-0.127^{\star *}$ & $(0.0513)$ & -0.00845 & $(0.0814)$ & $-0.0941^{* *}$ & $(0.0375)$ & 0.0176 & $(0.0471)$ \\
\hline $2004 q 3$ & -0.0521 & $(0.0383)$ & 0.0423 & $(0.0741)$ & $-0.0798^{\star}$ & $(0.0418)$ & 0.0255 & $(0.0531)$ \\
\hline $2004 q 4$ & - & - & - & - & - & - & - & - \\
\hline $2005 q 1$ & 0.00543 & $(0.0534)$ & 0.0290 & $(0.0648)$ & -0.0141 & $(0.0316)$ & -0.0307 & $(0.0342)$ \\
\hline $2005 q 2$ & $0.170^{* * *}$ & $(0.0567)$ & $-0.382^{* * *}$ & $(0.0882)$ & 0.00819 & $(0.0486)$ & $-0.198^{* * *}$ & $(0.0570)$ \\
\hline $2005 q 3$ & $0.167^{\star *}$ & $(0.0680)$ & $-0.593^{* * *}$ & $(0.108)$ & 0.0502 & $(0.0490)$ & $-0.389^{* * *}$ & $(0.0681)$ \\
\hline $2005 q 4$ & $0.195^{\star * *}$ & $(0.0722)$ & $-0.680^{\star * *}$ & $(0.104)$ & $0.0786^{*}$ & $(0.0448)$ & $-0.421^{* * *}$ & $(0.0719)$ \\
\hline $2006 q 1$ & $0.215^{\star \star \star}$ & $(0.0686)$ & $-0.724^{\star \star *}$ & $(0.102)$ & $0.107^{\star *}$ & $(0.0457)$ & $-0.452^{\star \star *}$ & $(0.0803)$ \\
\hline $2006 q 2$ & $0.291^{* * *}$ & $(0.0777)$ & $-0.817^{\star \star *}$ & $(0.112)$ & $0.211^{* * *}$ & $(0.0521)$ & $-0.505^{\star * *}$ & $(0.0936)$ \\
\hline $2006 q 3$ & $0.339^{* * *}$ & $(0.0800)$ & $-0.842^{* * *}$ & $(0.122)$ & $0.261^{* * *}$ & $(0.0625)$ & $-0.547^{* * *}$ & $(0.103)$ \\
\hline $2006 q 4$ & $0.436^{* * *}$ & $(0.0831)$ & $-0.869^{\star * *}$ & $(0.139)$ & $0.346^{\star * *}$ & $(0.0602)$ & $-0.526^{\star * *}$ & $(0.121)$ \\
\hline $2007 q 1$ & $0.457^{* * *}$ & $(0.0866)$ & $-0.877^{* * *}$ & $(0.140)$ & $0.388^{* * *}$ & $(0.0660)$ & $-0.532^{* * *}$ & $(0.126)$ \\
\hline $2007 q 2$ & $0.517^{* \star *}$ & (0.0883) & $-0.851^{* \star *}$ & $(0.168)$ & $0.429^{* \star *}$ & $(0.0674)$ & $-0.512^{* * *}$ & $(0.121)$ \\
\hline $2007 q^{3}$ & $0.552^{* * *}$ & $(0.0880)$ & $-0.840^{\star * *}$ & $(0.160)$ & $0.469^{* * *}$ & $(0.0705)$ & $-0.485^{\star * *}$ & $(0.122)$ \\
\hline $2007 q 4$ & $0.586^{\star * *}$ & $(0.0898)$ & $-0.748^{* * *}$ & $(0.158)$ & $0.527^{\star \star \star}$ & $(0.0720)$ & $-0.475^{\star \star \star}$ & $(0.127)$ \\
\hline $2008 q 1$ & $0.565^{\star \star *}$ & $(0.0888)$ & $-0.795^{\star \star \star}$ & $(0.154)$ & $0.573^{\star * *}$ & $(0.0723)$ & $-0.419^{\star * *}$ & $(0.128)$ \\
\hline Observations & & & & & & & 11 & \\
\hline R.-squared & & & & & & & 67 & \\
\hline
\end{tabular}

Note: Country dummies and constant term not reported. Standard errors are robust to heteroscedasticity and serial correlation 
Panel I

Panel J

\begin{tabular}{|c|c|c|c|c|c|c|c|c|}
\hline Banking Jur & \multicolumn{4}{|c|}{ Luxembourg } & \multicolumn{4}{|c|}{ Luxembourg } \\
\hline Treatment & \multicolumn{4}{|c|}{ EU15 } & \multicolumn{4}{|c|}{ EU15 } \\
\hline Control & \multicolumn{4}{|c|}{ NON-EU } & \multicolumn{4}{|c|}{ OECD } \\
\hline \multirow[t]{3}{*}{ Currency } & \multicolumn{4}{|c|}{ ALL } & \multicolumn{4}{|c|}{ ALL } \\
\hline & \multicolumn{2}{|c|}{ Time dummies (Dt) } & \multicolumn{2}{|c|}{ Interaction terms $\left(\mathrm{Dt}^{\star}{ }^{\star} \mathrm{EU}\right)$} & \multicolumn{2}{|c|}{ Time dummies (Dt) } & \multicolumn{2}{|c|}{ Interaction terms $\left(\mathrm{Dt}^{\star}{ }^{\star} \mathrm{EU}\right)$} \\
\hline & coefficient & se & coefficient & se & coefficient & se & coefficient & se \\
\hline $1995 q 4$ & $-0.360^{\star \star \star}$ & $(0.0978)$ & 0.209 & $(0.198)$ & -0.552 & $(0.324)$ & 0.402 & $(0.371)$ \\
\hline $1996 q 1$ & $-0.318^{* * *}$ & $(0.0985)$ & 0.192 & $(0.207)$ & $-0.481^{*}$ & $(0.272)$ & 0.355 & $(0.332)$ \\
\hline $1996 q 2$ & $-0.334^{* * *}$ & $(0.0905)$ & 0.230 & $(0.197)$ & -0.398 & $(0.267)$ & 0.294 & $(0.325)$ \\
\hline 1996q3 & $-0.320^{* * *}$ & $(0.0923)$ & 0.135 & $(0.214)$ & -0.258 & $(0.289)$ & 0.0733 & $(0.354)$ \\
\hline $1996 q 4$ & $-0.314^{* * *}$ & $(0.0867)$ & 0.134 & $(0.196)$ & $-0.475^{\star}$ & $(0.254)$ & 0.295 & $(0.314)$ \\
\hline $1997 q 1$ & $-0.368^{* * *}$ & $(0.0835)$ & 0.0946 & $(0.187)$ & $-0.554^{\star *}$ & $(0.252)$ & 0.281 & $(0.307)$ \\
\hline $1997 q 2$ & $-0.336^{\star * *}$ & $(0.0779)$ & 0.0822 & $(0.191)$ & $-0.488^{*}$ & $(0.257)$ & 0.234 & $(0.316)$ \\
\hline 1997q3 & $-0.344^{\star * *}$ & $(0.0778)$ & 0.0452 & $(0.175)$ & $-0.472^{*}$ & $(0.253)$ & 0.174 & $(0.303)$ \\
\hline $1997 q 4$ & $-0.303^{* * *}$ & $(0.0796)$ & 0.0454 & $(0.169)$ & $-0.484^{*}$ & $(0.256)$ & 0.227 & $(0.300)$ \\
\hline $1998 q 1$ & $-0.281^{* * *}$ & $(0.0818)$ & 0.0321 & $(0.167)$ & $-0.511^{*}$ & $(0.248)$ & 0.262 & $(0.291)$ \\
\hline $1998 q 2$ & $-0.253^{\star * *}$ & $(0.0797)$ & $9.67 e-05$ & $(0.154)$ & -0.432 & $(0.267)$ & 0.179 & $(0.301)$ \\
\hline 1998q3 & $-0.253^{\star * *}$ & $(0.0797)$ & $9.67 e-05$ & $(0.154)$ & -0.432 & $(0.267)$ & 0.179 & $(0.301)$ \\
\hline $1998 q 4$ & $-0.271^{* * *}$ & $(0.0738)$ & 0.0137 & $(0.151)$ & $-0.426^{*}$ & $(0.231)$ & 0.169 & $(0.269)$ \\
\hline $1999 q 1$ & $-0.334^{* * *}$ & $(0.0770)$ & 0.0302 & $(0.156)$ & $-0.470^{*}$ & $(0.238)$ & 0.166 & $(0.278)$ \\
\hline $1999 q 2$ & $-0.343^{* * *}$ & $(0.0788)$ & -0.0822 & $(0.140)$ & $-0.478^{\star *}$ & $(0.231)$ & 0.0530 & $(0.262)$ \\
\hline $1999 q 3$ & $-0.300^{* * *}$ & $(0.0769)$ & 0.0206 & $(0.145)$ & $-0.475^{\star}$ & $(0.233)$ & 0.195 & $(0.266)$ \\
\hline $1999 q 4$ & $-0.256^{* * *}$ & $(0.0761)$ & -0.110 & $(0.139)$ & $-0.492^{* *}$ & $(0.227)$ & 0.126 & $(0.258)$ \\
\hline $2000 q 1$ & $-0.304^{* * *}$ & $(0.0828)$ & -0.0550 & $(0.155)$ & $-0.569^{* * *}$ & $(0.185)$ & 0.209 & $(0.231)$ \\
\hline $2000 q 2$ & $-0.318^{* * *}$ & (0.0798) & -0.0732 & $(0.139)$ & $-0.558^{* *}$ & $(0.216)$ & 0.167 & $(0.247)$ \\
\hline $2000 q 3$ & $-0.316^{* * *}$ & (0.0789) & -0.00716 & $(0.123)$ & $-0.630^{* * *}$ & $(0.193)$ & 0.307 & $(0.217)$ \\
\hline $2000 q 4$ & $-0.259^{* * *}$ & (0.0801) & -0.0296 & $(0.118)$ & $-0.586^{\star * *}$ & $(0.200)$ & 0.297 & $(0.220)$ \\
\hline $2001 q 1$ & $-0.263^{* * *}$ & $(0.0724)$ & -0.0922 & $(0.129)$ & $-0.502^{* * *}$ & (0.0909) & 0.146 & $(0.145)$ \\
\hline $2001 q 2$ & $-0.290^{* * *}$ & $(0.0738)$ & -0.120 & $(0.123)$ & $-0.505^{* * *}$ & $(0.0964)$ & 0.0956 & $(0.141)$ \\
\hline $2001 q 3$ & $-0.224^{* * *}$ & $(0.0713)$ & -0.113 & $(0.120)$ & $-0.362^{* * *}$ & $(0.0812)$ & 0.0253 & $(0.131)$ \\
\hline $2001 q 4$ & $-0.230^{* * *}$ & $(0.0716)$ & -0.171 & $(0.110)$ & $-0.476^{* * *}$ & $(0.113)$ & 0.0746 & $(0.143)$ \\
\hline $2002 q 1$ & $-0.300^{* * *}$ & $(0.0678)$ & -0.0583 & (0.0995) & $-0.521^{* * *}$ & $(0.114)$ & 0.163 & $(0.137)$ \\
\hline $2002 q 2$ & $-0.258^{* * *}$ & $(0.0625)$ & 0.0186 & $(0.103)$ & $-0.455^{\star * *}$ & $(0.123)$ & 0.215 & $(0.150)$ \\
\hline $2002 q 3$ & $-0.246^{\star \star *}$ & $(0.0630)$ & -0.0738 & $(0.0845)$ & $-0.415^{\star \star *}$ & $(0.116)$ & 0.0959 & $(0.131)$ \\
\hline $2002 q 4$ & $-0.232^{\star \star *}$ & $(0.0618)$ & 0.0387 & $(0.0945)$ & $-0.419^{* * *}$ & $(0.0784)$ & $0.226^{\star *}$ & $(0.109)$ \\
\hline $2003 q 1$ & $-0.160^{* * *}$ & $(0.0544)$ & -0.113 & $(0.0936)$ & $-0.318^{* * *}$ & $(0.0934)$ & 0.0449 & $(0.123)$ \\
\hline $2003 q 2$ & $-0.135^{\star \star *}$ & $(0.0509)$ & 0.0773 & $(0.0814)$ & $-0.273^{\star \star *}$ & $(0.0821)$ & $0.215^{\star}$ & $(0.106)$ \\
\hline $2003 q 3$ & -0.0601 & $(0.0459)$ & -0.0227 & $(0.0889)$ & $-0.221^{* * *}$ & $(0.0639)$ & 0.138 & $(0.103)$ \\
\hline $2003 q 4$ & -0.0169 & $(0.0419)$ & 0.0108 & $(0.0614)$ & $-0.147^{\star}$ & $(0.0787)$ & 0.141 & $(0.0918)$ \\
\hline $2004 q 1$ & $-0.0894^{\star *}$ & $(0.0361)$ & 0.0760 & $(0.0592)$ & -0.141 & $(0.0888)$ & 0.127 & $(0.102)$ \\
\hline $2004 q 2$ & $-0.0894^{* * *}$ & $(0.0341)$ & 0.0487 & $(0.0657)$ & $-0.180^{*}$ & $(0.0962)$ & 0.140 & $(0.113)$ \\
\hline $2004 q 3$ & $-0.0987^{\star \star *}$ & $(0.0292)$ & 0.0674 & $(0.0461)$ & -0.0436 & $(0.0897)$ & 0.0122 & $(0.0973)$ \\
\hline $2004 q 4$ & - & - & - & - & - & - & - & - \\
\hline $2005 q 1$ & 0.0404 & $(0.0311)$ & 0.00171 & $(0.0470)$ & 0.00509 & $(0.0833)$ & 0.0371 & $(0.0912)$ \\
\hline $2005 q 2$ & -0.00566 & $(0.0350)$ & -0.0259 & $(0.0721)$ & 0.157 & $(0.127)$ & -0.188 & $(0.143)$ \\
\hline $2005 q 3$ & 0.0557 & $(0.0470)$ & -0.122 & $(0.0842)$ & 0.244 & $(0.152)$ & $-0.310^{*}$ & $(0.169)$ \\
\hline $2005 q 4$ & 0.0558 & $(0.0517)$ & $-0.189^{*}$ & $(0.1000)$ & $0.308^{*}$ & $(0.152)$ & $-0.441^{* *}$ & $(0.177)$ \\
\hline $2006 q 1$ & 0.0271 & (0.0399) & -0.0434 & $(0.136)$ & 0.194 & $(0.144)$ & -0.210 & $(0.198)$ \\
\hline $2006 q 2$ & $0.0747^{*}$ & $(0.0421)$ & -0.105 & $(0.133)$ & $0.318^{* *}$ & $(0.135)$ & $-0.348^{*}$ & (0.189) \\
\hline $2006 q 3$ & $0.121^{\star * *}$ & $(0.0430)$ & -0.161 & $(0.147)$ & $0.340^{* *}$ & $(0.159)$ & $-0.381^{*}$ & $(0.217)$ \\
\hline $2006 q 4$ & $0.205^{\star * *}$ & $(0.0447)$ & -0.0923 & $(0.180)$ & $0.487^{\star \star *}$ & $(0.166)$ & -0.374 & $(0.248)$ \\
\hline $2007 q 1$ & $0.234^{* * *}$ & $(0.0474)$ & $-0.255^{\star \star}$ & $(0.125)$ & $0.381^{* * *}$ & $(0.126)$ & $-0.402^{\star *}$ & $(0.175)$ \\
\hline $2007 q 2$ & $0.258^{* * *}$ & $(0.0527)$ & $-0.235^{\star}$ & $(0.140)$ & $0.385^{* * *}$ & $(0.116)$ & $-0.362^{*}$ & (0.179) \\
\hline $2007 q 3$ & $0.366^{* * *}$ & (0.0559) & -0.200 & $(0.166)$ & $0.549^{* *}$ & $(0.207)$ & -0.383 & $(0.265)$ \\
\hline $2007 q 4$ & $0.374^{* * *}$ & $(0.0591)$ & -0.173 & $(0.121)$ & $0.585^{* * *}$ & $(0.204)$ & -0.385 & $(0.232)$ \\
\hline $2008 q 1$ & $0.406^{* * *}$ & $(0.0613)$ & -0.0957 & $(0.121)$ & $0.587^{* * *}$ & $(0.206)$ & -0.276 & $(0.233)$ \\
\hline Observations & & & & & & & & \\
\hline R.-squared & & & & & & & & \\
\hline
\end{tabular}

Note: Country dummies and constant term not reported. Standard errors are robust to heteroscedasticity and serial correlation 
Panel K

Panel L

\begin{tabular}{|c|c|c|c|c|c|c|c|c|}
\hline \multirow{7}{*}{$\begin{array}{l}\text { Banking Jur } \\
\text { Treatment } \\
\text { Control } \\
\text { Currency } \\
\end{array}$} & & \\
\hline & \multicolumn{4}{|c|}{ Jersey } & \multicolumn{4}{|c|}{ Jersey } \\
\hline & \multicolumn{4}{|c|}{ EU15 } & \multicolumn{4}{|c|}{ EU15 } \\
\hline & \multicolumn{4}{|c|}{ NON-EU } & \multicolumn{4}{|c|}{ OECD } \\
\hline & \multicolumn{4}{|c|}{ ALL } & \multicolumn{4}{|c|}{ ALL } \\
\hline & \multicolumn{2}{|c|}{ Time dummies $(\mathrm{Dt})$} & \multicolumn{2}{|c|}{ Interaction terms $\left(\mathrm{Dt}^{*} \mathrm{EU}\right)$} & \multicolumn{2}{|c|}{ Time dummies $(\mathrm{Dt})$} & \multicolumn{2}{|c|}{ Interaction terms $\left(\mathrm{Dt}^{\star} \mathrm{EU}\right)$} \\
\hline & coefficient & se & coefficient & se & coefficient & se & coefficient & se \\
\hline \multicolumn{9}{|l|}{$1995 q 4$} \\
\hline $1996 q 1$ & & & & & & & & \\
\hline 1996q2 & & & & & & & & \\
\hline $1996 q 3$ & & & & & & & & \\
\hline $1996 q 4$ & & & & & & & & \\
\hline $1997 q 1$ & & & & & & & & \\
\hline $1997 q 2$ & & & & & & & & \\
\hline $1997 q 3$ & & & & & & & & \\
\hline $1997 q 4$ & & & & & & & & \\
\hline $1998 q 1$ & & & & & & & & \\
\hline 1998q2 & & & & & & & & \\
\hline $1998 q 3$ & & & & & & & & \\
\hline $1998 q 4$ & & & & & & & & \\
\hline 1999q1 & & & & & & & & \\
\hline $1999 q 2$ & & & & & & & & \\
\hline $1999 q 3$ & & & & & & & & \\
\hline $1999 q 4$ & & & & & & & & \\
\hline $2000 q 1$ & & & & & & & & \\
\hline $2000 q 2$ & & & & & & & & \\
\hline $2000 q 3$ & & & & & & & & \\
\hline $2000 q 4$ & & & & & & & & \\
\hline $2001 q 1$ & & & & & & & & \\
\hline $2001 q 2$ & & & & & & & & \\
\hline $2001 q 3$ & & & & & & & & \\
\hline $2001 q 4$ & $-0.308^{* * *}$ & $(0.0679)$ & -0.113 & $(0.139)$ & $-0.317^{*}$ & $(0.174)$ & -0.104 & $(0.215)$ \\
\hline $2002 q 1$ & -0.0609 & $(0.0639)$ & $-0.218^{*}$ & $(0.126)$ & 0.0622 & $(0.192)$ & -0.341 & $(0.223)$ \\
\hline $2002 q 2$ & -0.0734 & $(0.0614)$ & $-0.205^{*}$ & $(0.117)$ & -0.0550 & $(0.195)$ & -0.224 & $(0.221)$ \\
\hline $2002 q 3$ & -0.0906 & $(0.0644)$ & $-0.210^{*}$ & $(0.117)$ & -0.119 & $(0.155)$ & -0.182 & $(0.185)$ \\
\hline $2002 q 4$ & -0.0198 & $(0.0623)$ & $-0.176^{\star *}$ & $(0.0770)$ & -0.0817 & $(0.144)$ & -0.115 & $(0.151)$ \\
\hline $2003 q 1$ & 0.00636 & $(0.0702)$ & 0.0117 & $(0.167)$ & 0.0132 & $(0.121)$ & 0.00488 & $(0.199)$ \\
\hline $2003 q 2$ & 0.00715 & $(0.0690)$ & 0.0728 & $(0.140)$ & 0.0314 & $(0.0728)$ & 0.0486 & $(0.147)$ \\
\hline $2003 q 3$ & -0.0266 & $(0.0517)$ & 0.0307 & $(0.133)$ & 0.0585 & $(0.0518)$ & -0.0545 & $(0.139)$ \\
\hline $2003 q 4$ & 0.0498 & $(0.0500)$ & -0.0374 & $(0.137)$ & $0.0975^{\star}$ & $(0.0538)$ & -0.0850 & $(0.145)$ \\
\hline $2004 q 1$ & $0.0935^{*}$ & $(0.0494)$ & 0.0125 & $(0.110)$ & $0.106^{\star}$ & $(0.0537)$ & -0.000354 & $(0.116)$ \\
\hline $2004 q 2$ & 0.0106 & $(0.0359)$ & 0.0758 & $(0.0977)$ & 0.0558 & $(0.0519)$ & 0.0307 & $(0.108)$ \\
\hline $2004 q 3$ & 0.0104 & $(0.0382)$ & 0.0769 & $(0.0984)$ & 0.0817 & $(0.0489)$ & 0.00570 & $(0.107)$ \\
\hline $2004 q 4$ & - & - & - & - & - & - & - & - \\
\hline $2005 q 1$ & 0.00639 & $(0.0405)$ & 0.0396 & $(0.0581)$ & $0.168^{* \star *}$ & $(0.0381)$ & $-0.122^{\star *}$ & $(0.0579)$ \\
\hline $2005 q 2$ & $0.156^{* * *}$ & $(0.0431)$ & $-0.227^{\star \star \star}$ & $(0.0748)$ & $0.192^{\star * *}$ & $(0.0468)$ & $-0.263^{\star * *}$ & $(0.0794)$ \\
\hline $2005 q 3$ & $0.251^{\star \star *}$ & $(0.0509)$ & $-0.363^{\star \star \star}$ & $(0.0922)$ & $0.273^{\star * *}$ & $(0.0585)$ & $-0.386^{\star * \star}$ & $(0.0996)$ \\
\hline $2005 q 4$ & $0.198^{* * *}$ & $(0.0399)$ & $-0.298^{* * *}$ & $(0.0562)$ & $0.297^{* * *}$ & $(0.0628)$ & $-0.398^{* * *}$ & $(0.0753)$ \\
\hline $2006 q 1$ & $0.221^{* * *}$ & $(0.0487)$ & $-0.285^{\star * *}$ & $(0.0745)$ & $0.335^{\star * *}$ & $(0.0816)$ & $-0.399^{* * *}$ & $(0.101)$ \\
\hline $2006 q 2$ & $0.295^{\star \star *}$ & $(0.0415)$ & 0.154 & $(0.214)$ & $0.343^{* * *}$ & $(0.0692)$ & 0.106 & $(0.230)$ \\
\hline $2006 q 3$ & $0.299^{* * *}$ & $(0.0517)$ & $-0.332^{\star * *}$ & $(0.106)$ & $0.338^{* * *}$ & $(0.0609)$ & $-0.371^{* * *}$ & $(0.115)$ \\
\hline $2006 q 4$ & $0.367^{\star \star *}$ & $(0.0484)$ & $-0.370^{* * *}$ & $(0.0766)$ & $0.412^{\star * *}$ & $(0.0642)$ & $-0.415^{\star \star \star}$ & $(0.0894)$ \\
\hline $2007 q 1$ & $0.441^{* * *}$ & $(0.0520)$ & $-0.425^{\star * *}$ & $(0.0889)$ & $0.598^{* * *}$ & $(0.165)$ & $-0.582^{\star * *}$ & $(0.181)$ \\
\hline $2007 q 2$ & $0.485^{\star * *}$ & $(0.0549)$ & $-0.552^{* * *}$ & $(0.193)$ & $0.587^{* * *}$ & $(0.0718)$ & $-0.654^{* * *}$ & $(0.207)$ \\
\hline $2007 q 3$ & $0.534^{* * *}$ & $(0.0517)$ & $-0.558^{* * *}$ & $(0.185)$ & $0.644^{* * *}$ & $(0.0935)$ & $-0.668^{* * *}$ & $(0.209)$ \\
\hline $2007 q 4$ & $0.525^{* * *}$ & $(0.0616)$ & 0.0580 & $(0.220)$ & $0.583^{* * *}$ & $(0.0791)$ & 0.000834 & $(0.235)$ \\
\hline $2008 q 1$ & $0.538^{\star * *}$ & $(0.0562)$ & $-0.546^{* * *}$ & $(0.185)$ & $0.668^{* * *}$ & $(0.102)$ & $-0.676^{* * *}$ & $(0.211)$ \\
\hline Observations & & & & & & & & \\
\hline R.-squared & & & & & & & & \\
\hline
\end{tabular}

Note: Country dummies and constant term not reported. Standard errors are robust to heteroscedasticity and serial correlation 